ARTICLE

\title{
Reversible multicolor chromism in layered formamidinium metal halide perovskites
}

\author{
Bryan A. Rosales (10 1, Laura E. Mundt ${ }^{2}$, Taylor G. Allen (1) 1, David T. Moore (1) 1, Kevin J. Prince (i) 1,3,
} Colin A. Wolden ${ }^{3,4}$, Garry Rumbles ${ }^{1,5}$, Laura T. Schelhas (D) $^{2} \&$ Lance M. Wheeler $^{1 \times}$

Metal halide perovskites feature crystalline-like electronic band structures and liquid-like physical properties. The crystal-liquid duality enables optoelectronic devices with unprecedented performance and a unique opportunity to chemically manipulate the structure with low energy input. In this work, we leverage the low formation energy of metal halide perovskites to demonstrate multicolor reversible chromism. We synthesized layered Ruddlesden-Popper $\mathrm{FA}_{\mathrm{n}+1} \mathrm{~Pb}_{\mathrm{n}} \mathrm{X}_{3 \mathrm{n}+1}$ ( $\mathrm{FA}=$ formamidinium, $\mathrm{X}=\mathrm{I}, \mathrm{Br} ; n=$ number of layers $=1$, $2,3 \ldots \infty)$ and reversibly tune the dimensionality $(n)$ by modulating the strength and number of $\mathrm{H}$-bonds in the system. $\mathrm{H}$-bonding was controlled by exposure to solvent vapor (solvatochromism) or temperature change (thermochromism), which shuttles FAX salt pairs between the $\mathrm{FA}_{\mathrm{n}+1} \mathrm{~Pb}_{n} \mathrm{X}_{3 \mathrm{n}+1}$ domains and adjacent $\mathrm{FAX}$ "reservoir" domains. Unlike traditional chromic materials that only offer a single-color transition, $\mathrm{FA}_{n+1} \mathrm{~Pb}_{n} \mathrm{X}_{3 n+1}$ films reversibly switch between multiple colors including yellow, orange, red, brown, and white/ colorless. Each colored phase exhibits distinct optoelectronic properties characteristic of 2D superlattice materials with tunable quantum well thickness.

\footnotetext{
${ }^{1}$ Center for Chemistry and Nanoscience, National Renewable Energy Laboratory, 15013 Denver West Parkway, Golden, CO 80401, USA. ${ }^{2}$ SLAC National Accelerator Laboratory, 2575 Sand Hill Road, Menlo Park, CA 94025, USA. ${ }^{3}$ Department of Chemical and Biological Engineering, Colorado School of Mines, Golden, CO 80401, USA. ${ }^{4}$ Material Science Program, Colorado School of Mines, Golden, CO 80401, USA. ${ }^{5}$ Renewable and Sustainable Energy Institute, Department of Chemistry, University of Colorado Boulder, Boulder, CO 80309, USA. ${ }^{凶}$ email: lance.wheeler@nrel.gov
} 
M etal halide perovskite (MHP) materials have captured the imagination of the scientific community ${ }^{1-5}$. The coexistence of crystalline-like electronic band structure and liquid-like physical properties of MHP materials endows them with long carrier lifetimes, long carrier diffusion lengths, and exceptional defect tolerance to enable an array of exciting optoelectronic applications ${ }^{6}$. However, it is challenging to prevent changes in phase or composition of these "crystalline liquids" even in benign conditions. Despite issues with stability upon exposure to humidity, heat, and light ${ }^{8-10}$, MHPs have enabled solar cells with a record power conversion efficiency (PCE) $>25 \%{ }^{11}$.

Three-dimensional (3D) MHPs are composed of corner-sharing $\left[\mathrm{MX}_{6}\right]^{4-}$ octahedra $\left(\mathrm{M}=\mathrm{Pb}^{2+}, \mathrm{Sn}^{2+} ; \mathrm{X}=\mathrm{I}^{-}, \mathrm{Br}^{-}, \mathrm{Cl}^{-}\right)$that form an isotropic inorganic framework separated by A-site organic (methylammonium (MA), formamidinium (FA), etc.) or inorganic (alkali metal) monovalent cations. 2D MHPs also exhibit cornersharing $\left[\mathrm{MX}_{6}\right]^{4-}$ octahedra but only in two dimensions with the third dimension separated in space by the A-site cation ${ }^{12-14}$. 2D MHPs are classified as Ruddlesden-Popper ${ }^{15}$ or Dion-Jacobson ${ }^{16,17}$ phases of the general formula $A_{2}^{\prime} A_{n-1} M_{n} X_{3 n+1}$ or $A^{\prime} A_{n-1} M_{n} X_{3 n+1}$, respectively, where $\mathrm{A}^{\prime}=1+$ or $2+$ cation, $\mathrm{A}=1+$ cation, and $n=1$, $2,3, \ldots \infty$ is the number of connected $2 \mathrm{D}$ octahedra layers.

Chromogenic compounds change visible color when subjected to an external stimulus such as light, temperature, electric potential, solvent/vapor, or mechanical forces ${ }^{18-20}$. Materials that chromogenically change under these stimuli are classified as photochromic, thermochromic, electrochromic, solvatochromic, and mechanochromic, respectively ${ }^{18}$. Realizing reversible chromism in MHPs unlocks a new class of functional materials that couples a dynamic element to their remarkable optoelectronic properties. We envision dynamically tunable semiconductors to have applications that span switchable photovoltaics ${ }^{21,22}$ to energy storage ${ }^{23}$ and neuromorphic computing ${ }^{24}$. To date, there are two recognized mechanisms for reversible chromism in MHP materials: (1) crystal phase transformation $^{22}$ and (2) molecular intercalation ${ }^{21}$. Both of these mechanisms have enabled the first examples of switchable photovoltaic windows ${ }^{21,22}$, which circumvent the fundamental trade-off between power conversion and visible light transmittance of traditional photovoltaic windows ${ }^{25}$.

MHPs are inherently thermochromic materials exhibiting significant optical changes induced by crystal phase transitions between the $\alpha$-phase, a black high-symmetry perovskite phase composed of corner-sharing $\left[\mathrm{MX}_{6}\right]^{4-}$ octahedra, and the $\delta$-phase, a yellow-to-colorless non-perovskite hexagonal or orthorhombic phase composed of face- or edge-sharing $\left[\mathrm{MX}_{6}\right]^{4-}$ octahedra, respectively ${ }^{26-28}$. Utilizing this phase transformation, the mixedhalide perovskite $\mathrm{CsPb}_{0.5} \mathrm{Br}_{2.5}$ was employed in switchable photovoltiac window that achieved a $4.69 \%$ PCE with a phase transition temperature of $105^{\circ} \mathrm{C}^{22}$. However, it is challenging to achieve transition temperatures below $100^{\circ} \mathrm{C}$ for thermochromic window applications, and the smaller thermodynamic driving force at low temperature results in many hours for a complete phase transition ${ }^{22}$. In contrast, exposure of MHPs to vapor molecules that interact with the lattice can greatly decrease the temperature necessary for chromogenic behavior and improves transition speeds to seconds or minutes instead of hours as a result of the low formation/dissociation energy inherent in $\mathrm{MHPs}^{29-31}$. We have shown previously that exposure of $\mathrm{MAPbI}_{3}$ to methylamine vapor generates the clear $\mathrm{MAPbI}_{3} \cdot \mathrm{xCH}_{3} \mathrm{NH}_{2}$ complex, which can be switched back to black $\mathrm{MAPbI}_{3}$ when heated with solar illumination ${ }^{21}$. Others have shown that room temperature solvatochromism is possible through the intercalation of ethanol into $2 \mathrm{D} \mathrm{OA}_{2} \mathrm{MAPb}_{2} \mathrm{I}_{7}{ }^{32}$ or by forming reversible hydrates for the transition between 3D $\mathrm{MAPbBr}_{3}$ and $0 \mathrm{D}$ $\mathrm{MA}_{4} \mathrm{PbBr}_{6} \cdot 2 \mathrm{H}_{2} \mathrm{O}^{33}$. FA-based MHPs, unlike MA analogues, do not exhibit hydrate phases. Instead, exposure of $\alpha-\mathrm{FAPbI}_{3}$ to $\mathrm{H}_{2} \mathrm{O}$ catalytically converts the film into $\delta$ - $-\mathrm{FAPbI}_{3}$ by interacting with the anisotropically strained (111) $\alpha-\mathrm{FAPbI}_{3}$ lattice plane ${ }^{34-36}$.

In this work, we synthesize composite films composed of layered FA-based MHPs of the general formula $\mathrm{FA}_{\mathrm{n}+1} \mathrm{~Pb}_{\mathrm{n}} \mathrm{X}_{3 \mathrm{n}+1}$ $(\mathrm{X}=\mathrm{I}, \mathrm{Br})$ and their mixed-halide compositions. We leverage their liquid-like physical properties to demonstrate a third mechanism of dynamic chromism in MHPs through reversible layer formation and coalescence to form compounds that span $2 \mathrm{D} \mathrm{FA}_{2} \mathrm{PbX}_{4}(n=1)$ to $3 \mathrm{D} \alpha-\mathrm{FAPbX}_{3}(n=\infty)$ and finally $1 \mathrm{D}$ $\delta$ - $\mathrm{FAPbI}_{3}$. Reversible chromism is enabled by a second "reservoir" phase in the film composed of excess FAX salt, which allows FAX to reversibly shuttle between the reservoir and MHP layers. The mechanism is controlled by modulating the strength and number of H-bonds between the reservoir, MHP, and solvent vapor. Unlike previous reports on switchable MHPs that only switch between a single dark and a single light color $^{21,22}$, our composite $\mathrm{FA}_{\mathrm{n}+1} \mathrm{~Pb}_{\mathrm{n}} \mathrm{X}_{3 \mathrm{n}+1}$ films reversibly switch between a continuum of colors spanning yellow, orange, red, brown, and white/colorless. The colored phases are $2 \mathrm{D}$ superlattice materials with tunable quantum well thickness.

\section{Results}

Synthesis of layered formamidinium metal halide perovskites. Synthesis methods for free-standing powder and thin films of layered formamidinium metal halide perovskites were developed. We synthesized $\mathrm{FA}_{\mathrm{n}+1} \mathrm{~Pb}_{\mathrm{n}} \mathrm{X}_{3 \mathrm{n}+1}$ powder by ball-milling a mixture of 4:1 FAX: $\mathrm{PbX}_{2}$ for $60 \mathrm{~min}$ in an inert atmosphere. Wide-angle $\mathrm{X}$-ray scattering (WAXS) data shows that $\mathrm{FA}_{\mathrm{n}+1} \mathrm{~Pb}_{\mathrm{n}} \mathrm{I}_{3 \mathrm{n}+1}$ powder exhibits Bragg diffraction peaks that correspond to a mixture of $2 \mathrm{D}$ $\mathrm{FA}_{2} \mathrm{PbI}_{4}(n=1)$ with staggered octahedral layers and $3 \mathrm{D} \alpha-\mathrm{FAPbI}_{3}$ (3C/3R) that corresponds to $n \geq 2$ (Supplementary Fig. 1). Though predicted to exist ${ }^{37}$, we believe this is the first report of iodide compositions of $\mathrm{FA}_{n+1} \mathrm{~Pb}_{\mathrm{n}} \mathrm{X}_{3 \mathrm{n}+1}$, and our WAXS results are in excellent agreement with previously reported $\mathrm{MA}_{2} \mathrm{PbI}_{4}{ }^{38}$ and $\mathrm{FA}_{2} \mathrm{PbBr}_{4}{ }^{39}$. Several different structures have been observed during the formation of FA-based halide perovskites, including $2 \mathrm{H}, 4 \mathrm{H}$, $6 \mathrm{H}, 3 \mathrm{C}$, and 3R structures (Supplementary Fig. 2) ${ }^{40}$. Our WAXS data eliminates any significant contributions from hexagonal structures $(2 \mathrm{H}, 4 \mathrm{H}, 6 \mathrm{H})$. In the $\mathrm{FA}_{\mathrm{n}+1} \mathrm{~Pb}_{\mathrm{n}} \mathrm{X}_{3 \mathrm{n}+1}$ compounds observed here, $\mathrm{FA}^{+}$molecules separate the $2 \mathrm{D}$ layers rather than the long-chain or bulky cations typically used in other RuddlesdenPopper phases, such as butylammonium (13.4 ̊), phenylethylammonium $(16.6 \AA)$, and hexylammonium $(18.4 \AA)^{41,42}$. Here we observe a smaller interlayer spacing of $8.9 \AA$, determined from the (001) peak of $\mathrm{FA}_{2} \mathrm{PbI}_{4}$, which is approximately the length of two $\mathrm{FA}^{+}$molecules $(8.2 \AA$, see Methods section).

We produce functional thin films and expand to bromide alloys by developing a scaffold composite composed of $\mathrm{FA}_{\mathrm{n}+1} \mathrm{~Pb}_{\mathrm{n}} \mathrm{X}_{3 \mathrm{n}+1}$, an $\mathrm{FAX}$ reservoir, and a porous $\mathrm{Al}_{2} \mathrm{O}_{3}$ nanoparticle scaffold (Fig. 1a). Composite $\mathrm{FA}_{n+1} \mathrm{~Pb}_{n} \mathrm{X}_{3 \mathrm{n}+1}$ films are synthesized by spincoating a precursor solution containing $3 \mathrm{M} \mathrm{FAX}$ and $0.75 \mathrm{M} \mathrm{PbX}_{2}$ (4:1 FAX:PbX 2 ; $=\mathrm{I}, \mathrm{Br}$ ) in DMSO onto a $1.58 \pm 0.02 \mu \mathrm{m}$-thick $\mathrm{Al}_{2} \mathrm{O}_{3}$ scaffold. $\mathrm{FA}_{\mathrm{n}+1} \mathrm{~Pb}_{\mathrm{n}} \mathrm{X}_{3 \mathrm{n}+1}$ domains are formed by annealing the spin-coated film at $60^{\circ} \mathrm{C}$ for $10 \mathrm{~min}$. WAXS of composite $\mathrm{FA}_{\mathrm{n}+1} \mathrm{~Pb}_{\mathrm{n}} \mathrm{X}_{3 \mathrm{n}+1}$ films (Fig. 1b) match $\mathrm{FA}_{\mathrm{n}+1} \mathrm{~Pb}_{\mathrm{n}} \mathrm{I}_{3 \mathrm{n}+1}$ powder produced by ball-milling (Supplementary Fig. 1) and both exhibit a mixture of Bragg diffraction peaks that correspond to $2 \mathrm{D} \mathrm{FA}_{2} \mathrm{PbX}_{4}$ $(n=1)$ with staggered octahedral layers and $3 \mathrm{D} \alpha-\mathrm{FAPbX}_{3}(3 \mathrm{C} / 3 \mathrm{R})$. Specifically, we observe Bragg diffraction peaks at $0.703 \AA^{-1}$, $1.400 \AA^{-1}, 2.040 \AA^{-1}$, and $2.095 \AA^{-1}$ for $100 \%$ I and $0.738 \AA^{-1}$, $1.478 \AA^{-1}, 2.157 \AA^{-1}$, and $2.198 \AA^{-1}$ for $100 \%$ Br that correspond to the (001), (002), (201), and (003) planes of $2 \mathrm{D} \mathrm{FA}_{2} \mathrm{PbX}_{4}(n=1)$ (Fig. 1b, asterisks). The $100 \% \mathrm{Br}$ sample exhibits peaks shifted to higher $Q$ due to the smaller lattice constant associated the bromide anion. 
a

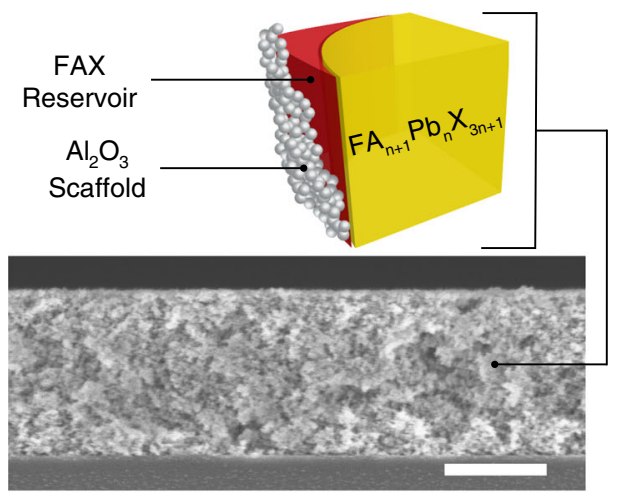

C

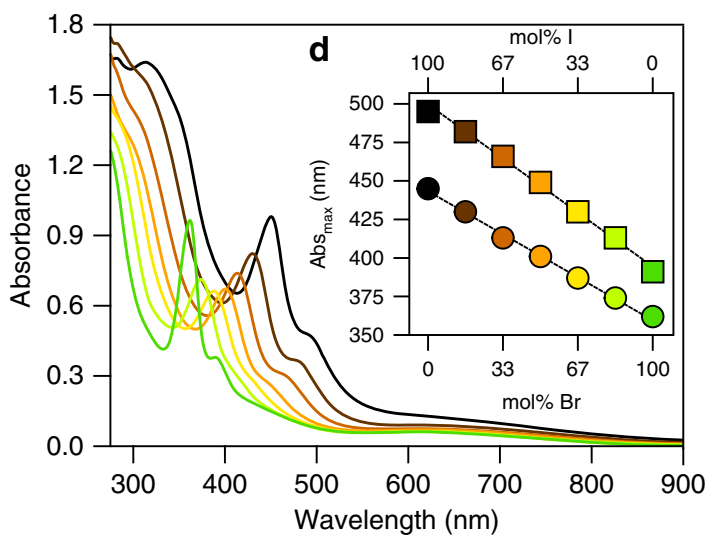

b

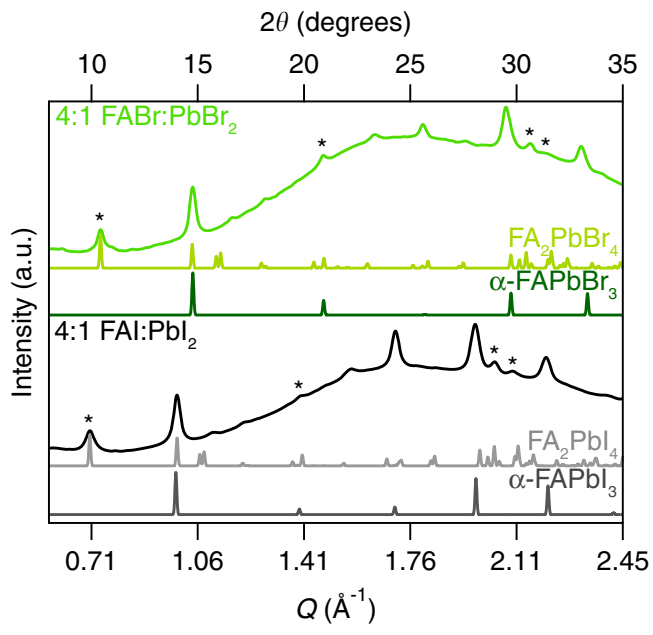

e

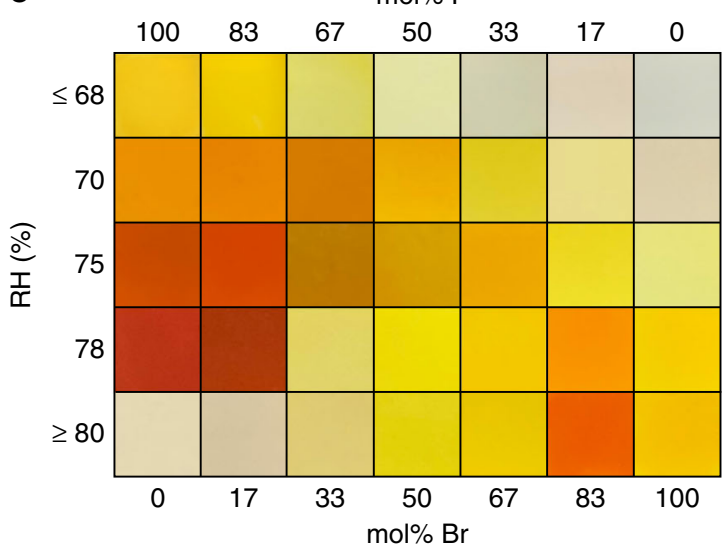

Fig. $1 \mathbf{F A}_{\mathbf{n}+\mathbf{1}} \mathbf{P b}_{\mathbf{n}} \mathbf{X}_{\mathbf{3 n + 1}}$ composite film characterization and reversible chromism. a Illustration showing the components of a $\mathrm{FA}_{\mathrm{n}+1} \mathrm{~Pb}_{n} \mathrm{X}_{3 \mathrm{n}+1}$ composite film, including $\mathrm{FA}_{n+1} \mathrm{~Pb}_{n} \mathrm{X}_{3 n+1}, \mathrm{FAX}$ reservoir, and $\mathrm{Al}_{2} \mathrm{O}_{3}$ scaffold. Scale bar is $1 \mu \mathrm{m}$. $\mathbf{b}$ Wide angle $\mathrm{X}$-ray scattering (WAXS) patterns of composite $\mathrm{FA}_{n+1} \mathrm{~Pb}_{n} \mathrm{X}_{3 \mathrm{n}+1}$ films. The $2 \theta$ axis in (b) is relative to $\mathrm{Cu} \mathrm{K \alpha}(1.5406 \AA$, $8.04 \mathrm{eV})$ radiation and was calculated from $\mathrm{Q}=4 \pi \sin (\theta) / \lambda$ where $\lambda$ is the excitation wavelength. The background scattering in (b) is caused by the $\mathrm{Al}_{2} \mathrm{O}_{3}$ scaffold and glass substrate. ${ }^{\star}=\mathrm{FA}_{2} \mathrm{PbX}_{4}$. Reference patterns of $\alpha$ - $\mathrm{FAPbl} \mathrm{P}_{3}$ were obtained from the Materials Design Group ${ }^{78}$, and the reference pattern of $\mathrm{FA}_{2} \mathrm{Pbl}_{4}$ was obtained from ref. ${ }^{37}$. Reference pattern of $\mathrm{FA}_{2} \mathrm{PbBr}_{4}$ was generated from $\mathrm{FA}_{2} \mathrm{Pbl}_{4}$ by substituting $\mathrm{Br}$ in place of I and multiplying the unit cell volume by the $\mathrm{Br} / \mathrm{I}$ radius ratio. c Absorbance spectra and $\mathbf{d}$ absorbance maxima as a function of composition for $\mathrm{FA}_{n+1} \mathrm{~Pb}_{n} \mathrm{X}_{3 n+1}$ films. Circles in $\mathbf{d}$ correspond to the strong excitonic peak tunable between 450 and $360 \mathrm{~nm}(n=1)$ while squares correspond to the absorption edge tunable between 500 and $390 \mathrm{~nm}(n>1)$, respectively. e Representative optical photographs of composite $\mathrm{FA}_{\mathrm{n}+1} \mathrm{~Pb}_{n} \mathrm{X}_{3 \mathrm{n}+1}$ films highlighting the diverse colors obtainable upon exposure to humidity. $\left[\mathrm{Pbl}_{2}\right]=0.75 \mathrm{M}$ in dimethyl sulfoxide (DMSO) was held constant in all precursors, which were spun onto a $1.58 \pm 0.02 \mu \mathrm{m} \mathrm{Al} \mathrm{O}_{3}$ scaffold and annealed at $60^{\circ} \mathrm{C}$ for 10 min. Note that films rich in iodide $(>80 \% \mathrm{l})$ or bromide $(>67 \% \mathrm{Br}$ ) bleach to white/transparent upon exposure to $>80 \%$ or $<68 \%$ relative humidity $(\mathrm{RH})$, respectively.

The optically active crystalline $\mathrm{FA}_{\mathrm{n}+1} \mathrm{~Pb}_{\mathrm{n}} \mathrm{X}_{3 \mathrm{n}+1}(\mathrm{X}=\mathrm{I}, \mathrm{Br})$ domains are composed of predominantly $n=1$ and $n=2$ layers. $\mathrm{FA}_{\mathrm{n}+1} \mathrm{~Pb}_{\mathrm{n}} \mathrm{X}_{3 \mathrm{n}+1}$ domains exhibit compositionally tunable optical properties that vary linearly as the halide ratio is varied from $100 \%$ iodide to $100 \%$ bromide (Fig. 1c, d) with two absorption peaks: (1) a strong excitonic peak tunable between 450 and $360 \mathrm{~nm}$ (circles) and (2) an absorption edge tunable between 500 and $390 \mathrm{~nm}$ (squares) that correspond to $n=1$ and $n=2$ layers, respectively. The optical properties observed for composite $\mathrm{FA}_{\mathrm{n}+1} \mathrm{~Pb}_{\mathrm{n}} \mathrm{X}_{3 \mathrm{n}+1}$ films are consistent with other 2D MHPs ${ }^{41,43-46}$.

Reversible chromism in layered FA-based MHPs. Composite $\mathrm{FA}_{\mathrm{n}+1} \mathrm{~Pb}_{\mathrm{n}} \mathrm{X}_{3 \mathrm{n}+1}$ films show a brilliant array of reversible coloration upon exposure to solvent vapor. The visual appearance of composite $\mathrm{FA}_{\mathrm{n}+1} \mathrm{~Pb}_{\mathrm{n}} \mathrm{X}_{3 \mathrm{n}+1}$ films range from colorless to yellow, orange, red, and brown (Fig. 1e). We attribute the mechanism of color change to a dynamic equilibrium between FAX salt pairs intercalated into the $\mathrm{FA}_{\mathrm{n}+1} \mathrm{~Pb}_{\mathrm{n}} \mathrm{X}_{3 \mathrm{n}+1}$ domain or shuttled to an adjacent amorphous "reservoir" domain composed of excess FAX
(Fig. 1e). The equilibrium is described by Eq. 1 (see Supplementary Note 1 for a derivation of $q$ ):

$$
\begin{gathered}
\mathrm{FA}_{\mathrm{n}+1} \mathrm{~Pb}_{\mathrm{n}} \mathrm{X}_{3 \mathrm{n}+1} \leftrightarrow \mathrm{FA}_{\mathrm{n}+1-q} \mathrm{~Pb}_{\mathrm{n}} \mathrm{X}_{3 n+1-q}+\mathrm{qFAX} \\
n=1,2,3, \ldots \infty ; q=\frac{1}{n(n+1)}
\end{gathered}
$$

The dynamic equilibrium is shifted by modulating the strength and number of $\mathrm{H}$-bonds between solvent molecules, reservoir, and MHP. This insight allows us to design composite materials composed of $\mathrm{FA}_{\mathrm{n}+1} \mathrm{~Pb}_{\mathrm{n}} \mathrm{X}_{3 \mathrm{n}+1}$ domains that change color in response to solvent vapor (solvatochromism) or temperature (thermochromism) by reversibly forming compounds that span $2 \mathrm{D} \mathrm{FA}_{2} \mathrm{PbX}_{4}(n=1)$ to $3 \mathrm{D}$ a-FAPbX $(n=\infty)$ and finally $1 \mathrm{D}$ $\delta-\mathrm{FAPbI}_{3}$ (Fig. 2).

There are three main drivers in the design of composite thin films: (1) $\mathrm{FA}_{\mathrm{n}+1} \mathrm{~Pb}_{\mathrm{n}} \mathrm{X}_{3 \mathrm{n}+1}$ domains must be accessible to solvent vapor, (2) a reservoir phase must be present, and (3) the solvent vapor must interact favorably with $\mathrm{FA}_{\mathrm{n}+1} \mathrm{~Pb}_{\mathrm{n}} \mathrm{X}_{3 \mathrm{n}+1}$. In order to 


\section{Decreasing H-Bonding}

a

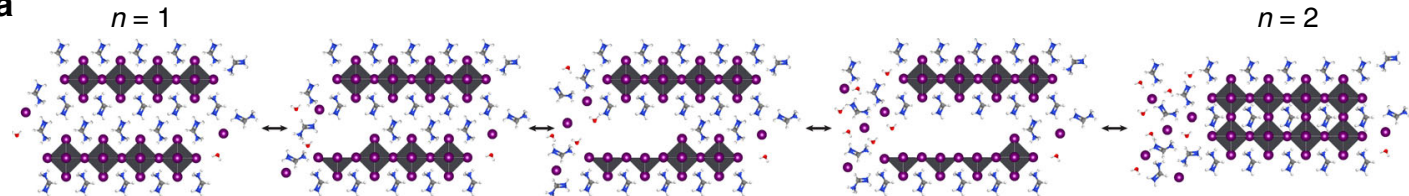

b

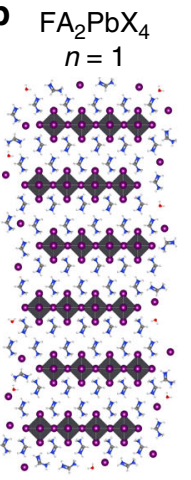

$\mathrm{FA}_{3} \mathrm{~Pb}_{2} \mathrm{X}_{7}$ $n=2$

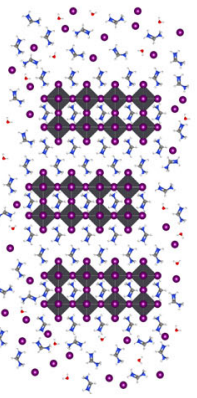

$\mathrm{FA}_{4} \mathrm{~Pb}_{3} \mathrm{X}_{10}$ $n=3$ $x \div 0.00$ 400
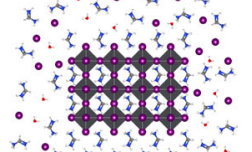

$j^{0} c^{2} c^{2} x^{0}$

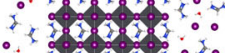

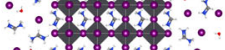

$\therefore$ roy 0

$300+00$

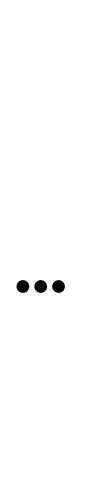

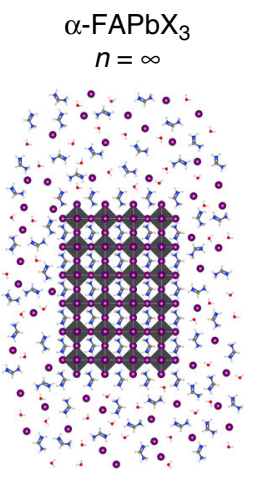

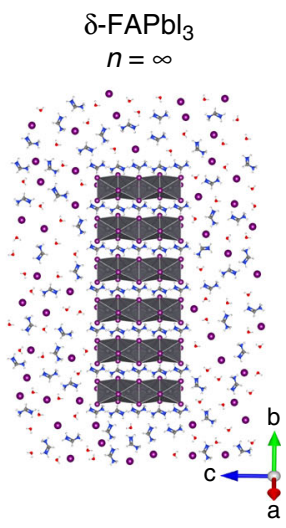

Fig. 2 Mechanism of multicolor chromism in layered formamidinium metal halide perovskites. a Reversible FAX shuttling between the FAX reservoir and layered metal halide perovskite (MHP) causes layer formation and coalescence. $\mathbf{b}$ Illustration of the reversible switching mechanism in chromic composite $\mathrm{FA}_{n+1} \mathrm{~Pb}_{n} \mathrm{X}_{3 n+1}\left(X=\mathrm{I}, \mathrm{Br}\right.$ ) films enabled by a FAX reservoir adjacent to $\mathrm{FA}_{n+1} \mathrm{~Pb}_{n} \mathrm{X}_{3 n+1}$ domains. Each colored film is a mixture of multiple thicknesses ( $n$ ).

provide solvent access, $\mathrm{FA}_{\mathrm{n}+1} \mathrm{~Pb}_{\mathrm{n}} \mathrm{X}_{3 \mathrm{n}+1}$ domains are formed in a mesoporous $\mathrm{Al}_{2} \mathrm{O}_{3}$ nanoparticle scaffold. The scaffold limits the size of the $\mathrm{FA}_{\mathrm{n}+1} \mathrm{~Pb}_{\mathrm{n}} \mathrm{X}_{3 \mathrm{n}+1}$ domains and provides a pathway for solvent vapor transport. The reservoir phase is formed by using an excess of FAX relative to $\mathrm{PbX}_{2}\left(>3: 1\right.$ FAX: $\mathrm{PbI}_{2}$ ). Solvent molecules and water in the composite film are maintained by annealing at low temperatures $\left(60^{\circ} \mathrm{C}\right)$ in a $40 \%$ relative humidity (RH) atmosphere without exposure to dry-air flow. A detailed discussion and explanation for composite $\mathrm{FA}_{\mathrm{n}+1} \mathrm{~Pb}_{\mathrm{n}} \mathrm{X}_{3 \mathrm{n}+1}$ film formation is supplied in Supplementary Note 2 and Supplementary Figs. 3-9. When assembled properly, composite films will reversibly change color rapidly $(<1-20$ min depending on solvent vapor flow rate) and over many cycles $(>10)$. Though ball-milled powder samples show a chromogenic response to solvent vapor, the transitions are slower $(30 \mathrm{~min}-1 \mathrm{~h})$ with limited reversibility (Supplementary Fig. 10).

The final design criterium is choice of solvent vapor. Reversible chromism of composite $\mathrm{FA}_{n+1} \mathrm{~Pb}_{n} \mathrm{X}_{3 \mathrm{n}+1}$ films is strongly dependent on the affinity of the solvent vapor to form $\mathrm{H}$-bonds with the FAX reservoir and $\mathrm{FA}_{\mathrm{n}+1} \mathrm{~Pb}_{\mathrm{n}} \mathrm{X}_{3 \mathrm{n}+1}$ constituents. A variety of solvent vapors were used to highlight the dependence on H-bonding (Supplementary Fig. 11). Chloroform and dichloromethane (DCM) have Lewis acidic protons that are $\mathrm{H}$-bond donors but have no significant $\mathrm{H}$-bond acceptor character. Tetrahydrofuran (THF) and pyridine have oxygen or nitrogen Lewis basic groups, respectively, that are $\mathrm{H}$ bond acceptors. Composite $\mathrm{FA}_{\mathrm{n}+1} \mathrm{~Pb}_{\mathrm{n}} \mathrm{X}_{3 \mathrm{n}+1}$ films exposed to chloroform, DCM, or THF do not noticeably change color, whereas pyridine bleaches the film to colorless. The stronger Lewis basicity of the pyridine compared to THF leads to solvation and complex formation with $\left[\mathrm{PbX}_{6}\right]^{4-}$ to form isolated octahedra. The ability of the solvent to both donate and accept $\mathrm{H}$-bonds is critical for reversible switching to occur. Solvent vapors such as water or alcohols (methanol, ethanol, and isopropyl alcohol) with H-bond-active hydroxyl groups will deeply color composite $\mathrm{FA}_{\mathrm{n}+1} \mathrm{~Pb}_{\mathrm{n}} \mathrm{X}_{3 \mathrm{n}+1}$ films from yellow to orange, red, and brown (Supplementary Fig. 11).

Molecular interactions in reversible chromism. H-bonds are the thermodynamic driving force for the reversible chromism in composite $\mathrm{FA}_{\mathrm{n}+1} \mathrm{~Pb}_{\mathrm{n}} \mathrm{I}_{3 \mathrm{n}+1}$ films. Chromism is dependent on both the strength and number of $\mathrm{H}$-bonds. For instance, color change induced by exposure to solvent vapor (solvatochromism) may be reversed by increasing the temperature of the film (thermochromism) if the vapor concentration is held constant. The thermochromic effect is a function of the strength of $\mathrm{H}$-bonding in the system, as the relative strength of H-bonds is weakened when heated and strengthened when cooled. We observe this effect with only mild conditions where a bleached film will rapidly $(<10 \mathrm{~s})$ convert to brown upon heating the film to $35^{\circ} \mathrm{C}$ (Supplementary Fig. 12), which nicely resides in the desirable range for thermochromic window applications ${ }^{21}$.

The remainder of the discussion centers around chromism induced by a change in the number of $\mathrm{H}$-bonds, rather than strength, to manipulate the thermodynamic equilibrium of Eq. 1. We control the number of $\mathrm{H}$-bonds by either changing the relative amount of the $\mathrm{FA}_{n+1} \mathrm{~Pb}_{\mathrm{n}} \mathrm{X}_{3 \mathrm{n}+1}$ phase to the reservoir phase or by changing the concentration of solvent vapor in the environment. We chose $\mathrm{FA}_{\mathrm{n}+1} \mathrm{~Pb}_{\mathrm{n}} \mathrm{I}_{3 \mathrm{n}+1}$ /water vapor as a model system since water vapor affords facile control over $\mathrm{RH}$ (concentration) compared to the partial pressure of other solvents and fast solvatochromic (hygrochromic) switching of $<1-20 \mathrm{~min}$ depending on water vapor flow rate. A switching time of $<7 \mathrm{~s}$ is shown in Supplementary Movie 1. We believe these observations are representative of the underlying mechanism, regardless of choice of chemical system.

We probe molecular interactions in the $\mathrm{FA}_{\mathrm{n}+1} \mathrm{~Pb}_{\mathrm{n}} \mathrm{I}_{3 \mathrm{n}+1} /$ water vapor model system by varying the $\mathrm{RH}$ between 17 and $83 \%$ $\mathrm{RH}$ in conjunction with in-situ diffuse-reflectance infrared Fourier 


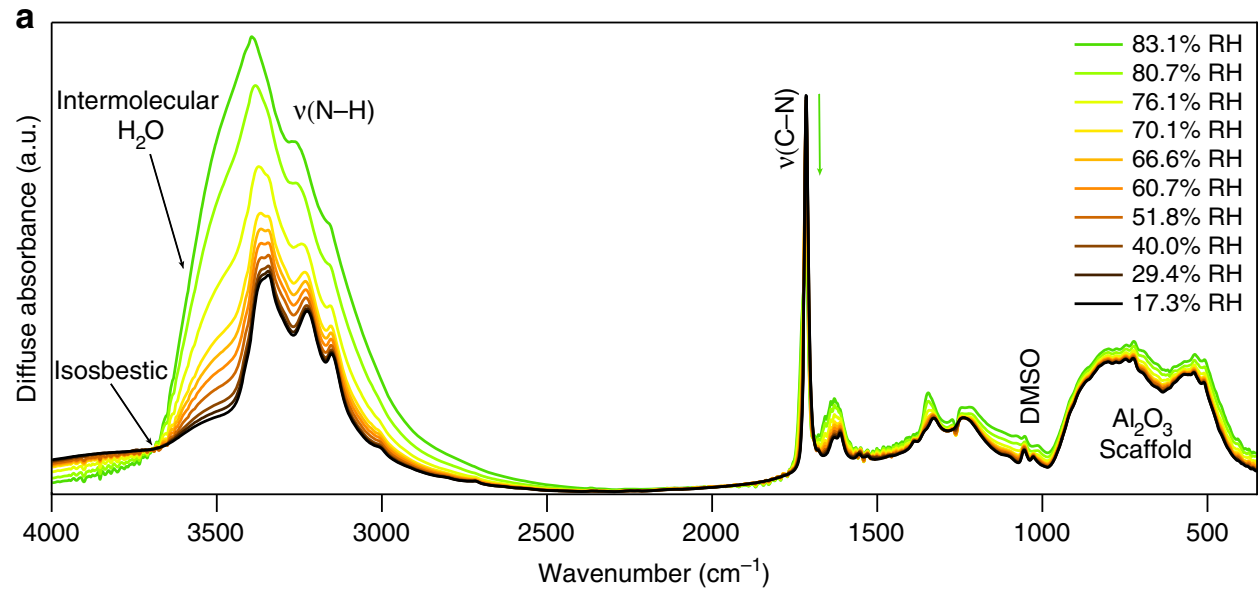

b

C
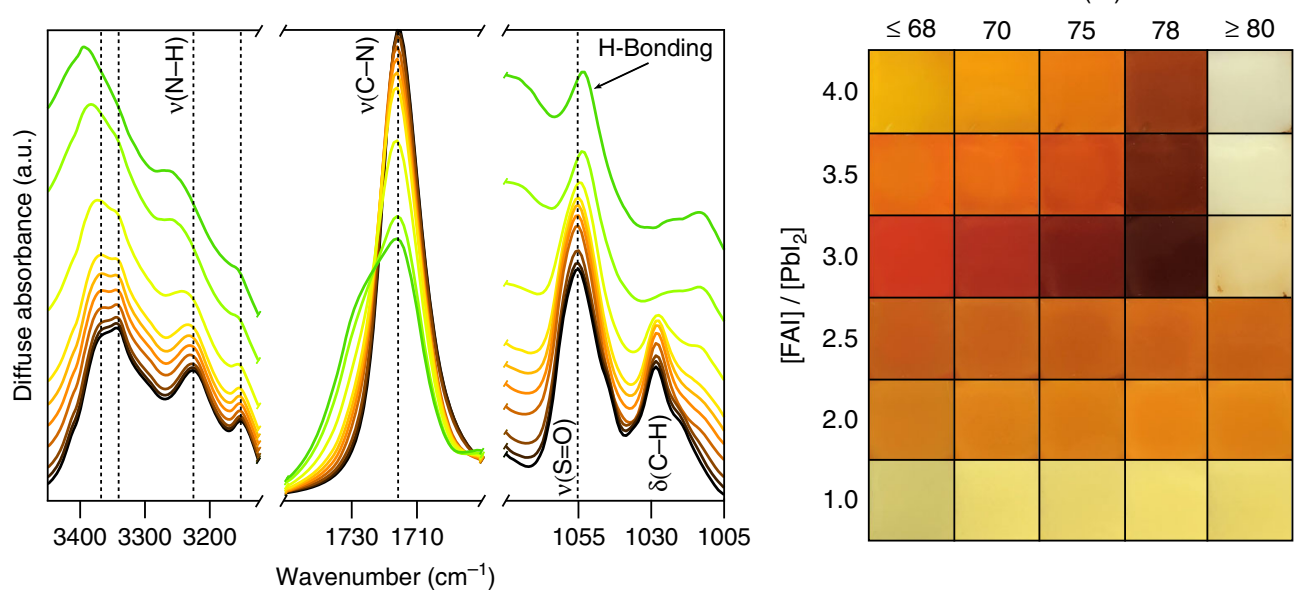

Fig. 3 Molecular interactions are the thermodynamic driving force for reversible chromism. a Representative diffuse-reflectance infrared Fourier transform spectroscopy (DRIFTS) spectra collected at various relative humidity $(\mathrm{RH})$ and extracted from Supplementary Fig. 13. b Spectra focused on the $\mathrm{H}$-bonding regions of the composite film: $\mathrm{N}-\mathrm{H}$ stretch region of $\mathrm{FA}^{+}, \mathrm{C}-\mathrm{N}$ asymmetric stretch region of $\mathrm{FA}^{+}$, and the $\mathrm{S}=\mathrm{O}$ stretch and $\mathrm{C}-\mathrm{H}$ rocking regions of dimethyl sulfoxide (DMSO). Dashed vertical lines indicate peak location at 17.3\% RH. c Optical photographs showing the effect of changing the number of molecular interactions on the hygrochromic properties by varying the $\mathrm{FAl}: \mathrm{Pbl}_{2}$ ratio and $\mathrm{RH}$. $\left[\mathrm{Pbl}_{2}\right]=0.75 \mathrm{M}$ in DMSO was held constant in all precursors, which were spun onto a $1.58 \pm 0.02 \mu \mathrm{m} \mathrm{Al} \mathrm{O}_{3}$ scaffold and annealed at $60^{\circ} \mathrm{C}$ for $10 \mathrm{~min}$. DRIFTS spectra and optical photographs were collected on films with a $\mathrm{FAl}: \mathrm{Pbl}_{2}$ ratio of 4.0 .

transform spectroscopy (DRIFTS). The DRIFTS spectrum collected at $17.3 \% \mathrm{RH}$ clearly shows vibrational modes corresponding to the components of the reservoir. The FAI is represented by $\mathrm{N}-\mathrm{H}$ stretching modes between 3400 and $3200 \mathrm{~cm}^{-1}$ and C-N asymmetric stretching at $1716 \mathrm{~cm}^{-1}$ correspond to the $\mathrm{FA}^{+}$cation $^{47}$. We also observe DMSO, $\mathrm{H}_{2} \mathrm{O}$, and the $\mathrm{Al}_{2} \mathrm{O}_{3}$ scaffold (Fig. 3a, black spectrum): $\mathrm{C}-\mathrm{H}$ bending modes between 1400 and $1300 \mathrm{~cm}^{-1}, \mathrm{~S}=\mathrm{O}$ stretching at $1056 \mathrm{~cm}^{-1}$, and $\mathrm{C}-\mathrm{H}$ rocking at $1028 \mathrm{~cm}^{-1}$ corresponding to $\mathrm{DMSO}^{48} ; \mathrm{H}-\mathrm{O}-\mathrm{H}$ bending at $1630 \mathrm{~cm}^{-1}$ and $\mathrm{O}-\mathrm{H}$ stretching at $3510 \mathrm{~cm}^{-1}$ corresponding to intermolecularly bound $\mathrm{H}_{2} \mathrm{O}^{49,50}$; and $\mathrm{Al}-\mathrm{O}$ stretching between 1000 and $500 \mathrm{~cm}^{-1}$ corresponding to the $\mathrm{Al}_{2} \mathrm{O}_{3}$ scaffold ${ }^{51}$.

We increase the number of $\mathrm{H}$-bonds by increasing $\mathrm{RH}$ from $17.3 \%$ to $83.1 \%$. The film changes color from yellow to orange to brown to white/colorless (Fig. 3c, top row), and the DRIFTS spectra correspondingly undergo several changes. Before a change in color occurs $(\mathrm{RH}<70 \%)$, the increased intensity of the $\mathrm{O}-\mathrm{H}$ stretching mode located between 3550 and $3200 \mathrm{~cm}^{-1}$ suggests increasing amounts of $\mathrm{H}_{2} \mathrm{O}$ are incorporated into the film and are intermolecularly $\mathrm{H}$-bonded with other $\mathrm{H}_{2} \mathrm{O}$ molecules or with FAI in the reservoir ${ }^{49,50}$. The isosbestic point at $3688 \mathrm{~cm}^{-1}$ signifies a reduction in scaffold-bonded $\mathrm{H}_{2} \mathrm{O}\left(>3688 \mathrm{~cm}^{-1}\right)$ and an increase in intermolecularly $\mathrm{H}$-bonded $\mathrm{H}_{2} \mathrm{O}$ or hydrated FAI $\left(3550-3200 \mathrm{~cm}^{-1} \text {, Fig. 3a }\right)^{48}$.

We observe a threshold value for chromism at c.a. $70 \% \mathrm{RH}$, which results in more dramatic changes to the DRIFTS spectra. The $\mathrm{H}$-bond interactions shift the thermodynamic equilibrium (Eq. 1) from the $\mathrm{FA}_{\mathrm{n}+1} \mathrm{~Pb}_{\mathrm{n}} \mathrm{I}_{3 \mathrm{n}+1}$ domains to the $\mathrm{FAI}$ reservoir, indicated by an increase in spectral intensity, peak shifting, and peak broadening at $\mathrm{RH}>70 \%$. The $\mathrm{N}-\mathrm{H}$ stretching modes broaden and blueshift, indicating the bonding environment of $\mathrm{FA}^{+}$is changing over time as it is shuttled from the $\mathrm{FA}_{\mathrm{n}+1} \mathrm{~Pb}_{\mathrm{n}} \mathrm{X}_{3 \mathrm{n}+1}$ domain to the reservoir (Fig. 3b). The broadening is accompanied by a shoulder that grows in at $1730 \mathrm{~cm}^{-1}$ (Fig. 3b). The blueshift at high RH indicates both shortening and strengthening of the $\mathrm{N}-\mathrm{H}$ bond ${ }^{52}$ as a result of $\mathrm{H}$-bond formation. Both $\mathrm{S}=\mathrm{O}$ stretch and $\mathrm{C}-\mathrm{H}$ rocking modes of DMSO remaining in the film redshift at higher $\mathrm{RH}$ values, which is characteristic with H-bonding to water and a distinct change in bonding environment (Fig. 3b) ${ }^{48}$. Although solvatochromism in our ball-milled powder synthesized without solvent (Supplementary Fig. 10) shows that DMSO is not crucial to the reversible switching mechanism, DMSO may facilitate switching by providing $\mathrm{H}$-bond acceptor sites. The molecular interactions observed in DRIFTS during color change from yellow to orange, brown, and colorless are 
reversed upon removal of water vapor (Supplementary Fig. 13). Removal of H-bond interactions shift the thermodynamic equilibrium (Eq. 1) from the reservoir back to the $\mathrm{FA}_{n+1} \mathrm{~Pb}_{n} \mathrm{I}_{3 n+1}$ domains.

The reservoir volume also dictates the number of molecular interactions and the resulting color of the $\mathrm{FA}_{n+1} \mathrm{~Pb}_{\mathrm{n}} \mathrm{I}_{3 \mathrm{n}+1}$ composite. Hygrochromic properties are only observed when the FAI: $\mathrm{PbI}_{2}$ ratio is $>3.0$, which suggests that enough FAI must be present to form both the reservoir and the layered $\mathrm{FA}_{\mathrm{n}+1} \mathrm{~Pb}_{\mathrm{n}} \mathrm{I}_{3 \mathrm{n}+1}$. As the $\mathrm{FAI}: \mathrm{PbI}_{2}$ ratio increases, the number of molecular interaction sites increases in the film. The color of the film changes from red to orange to yellow as the equilibrium is pushed to thinner layers (smaller $n$ ) with higher $\mathrm{FAI}: \mathrm{PbI}_{2}$ ratios. Thus, by controlling the number of molecular interactions through varying both the $\mathrm{RH}$ and the $\mathrm{FAI}: \mathrm{PbI}_{2}$ ratio, the chromic response of the film can be extensively controlled with a wide variety of colors obtainable, including yellow, orange, red, brown, dark brown, and white/transparent. We note the 2D nature of our films lead to significantly improved moisture stability as evidenced by repeated and reversible color cycling between 20 and $82 \% \mathrm{RH}$, storage at $\leq 40 \% \mathrm{RH}$ in air for months, and storage at $75 \% \mathrm{RH}$ in air for over one month.

Structural evolution due to molecular interactions. We probe the structural response of $\mathrm{FA}_{\mathrm{n}+1} \mathrm{~Pb}_{\mathrm{n}} \mathrm{I}_{3 \mathrm{n}+1}$ composites induced by molecular interactions using in-situ WAXS experiments. In-situ WAXS experiments nicely illustrate the reversible transformation from predominantly $\mathrm{FA}_{\mathrm{n}+1} \mathrm{~Pb}_{\mathrm{n}} \mathrm{I}_{3 \mathrm{n}+1}$ domains with $n=1,2$ to $\alpha-\mathrm{FAPbI}_{3}(n=\infty)$ and finally $\delta-\mathrm{FAPbI}_{3}$. Starting at ambient $\mathrm{RH}$, the films are exposed to humid air controlled at $82 \% \mathrm{RH}$. Dry conditions $(\sim 40 \% \mathrm{RH})$ are achieved by flowing Helium. The films are cycled through humid/dry conditions three times during collection of in-situ WAXS data (Fig. 4a). Flowing humid air at $82 \% \mathrm{RH}$ causes Bragg peaks corresponding to $\mathrm{FA}_{2} \mathrm{PbI}_{4}$ and $a-\mathrm{FAPbI}_{3}$ to gradually disappear over $10.5 \mathrm{~min}$ and $18 \mathrm{~min}$, respectively, while Bragg peaks corresponding to $\delta-\mathrm{FAPbI}_{3}$ begin to emerge at $9 \mathrm{~min}$. Disappearance of $\mathrm{FA}_{2} \mathrm{PbI}_{4}$ peaks in the WAXS pattern before $\alpha-\mathrm{FAPbI}_{3}$ peaks disappear suggests $n=1$ layers coalesce to form layers of $n>1$. a

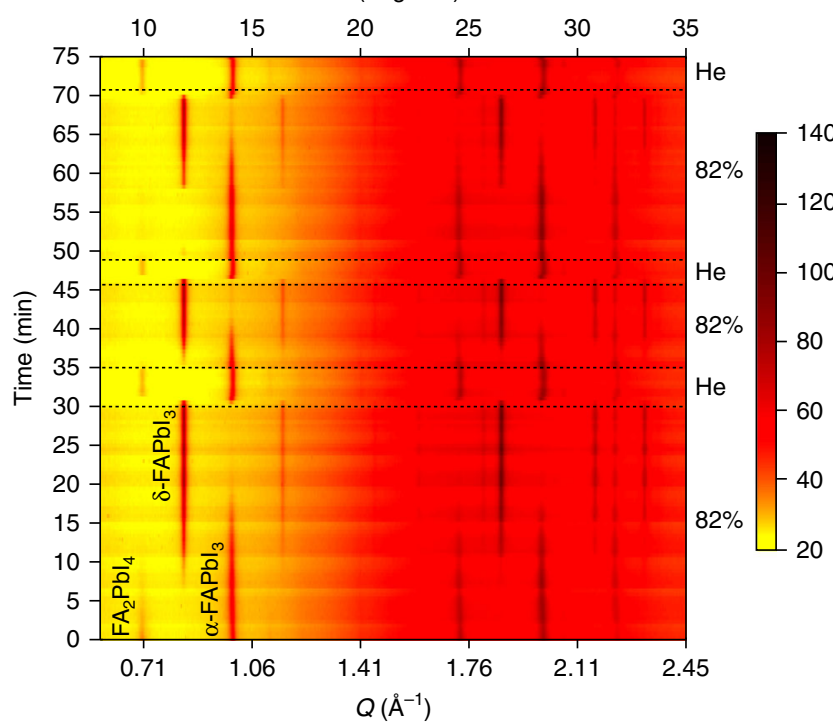

b

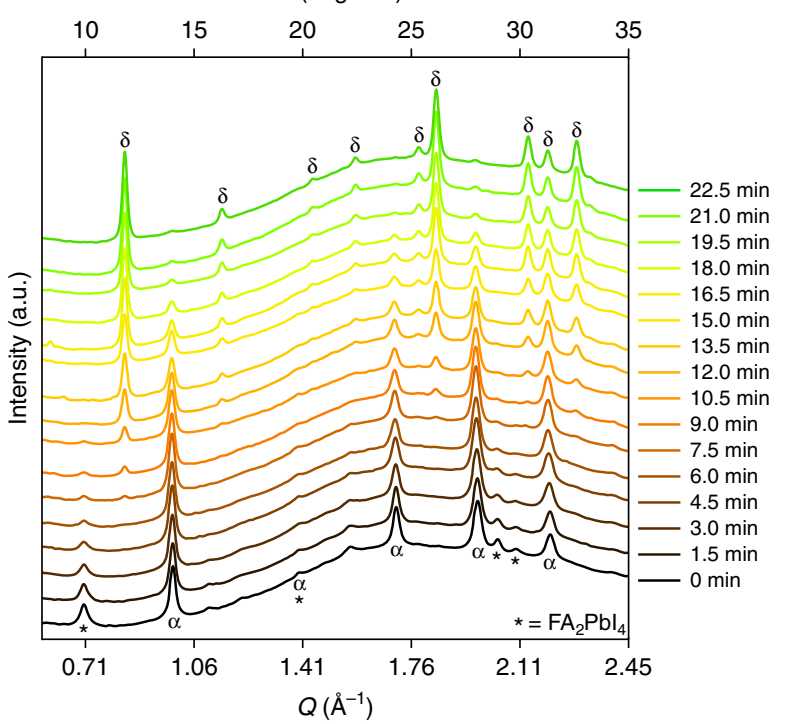

$\mathbf{f}$

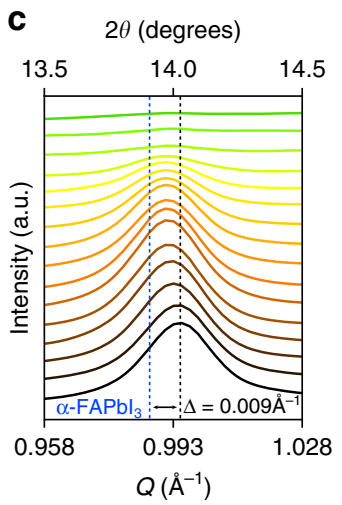

d $2 \theta$ (degrees)

e
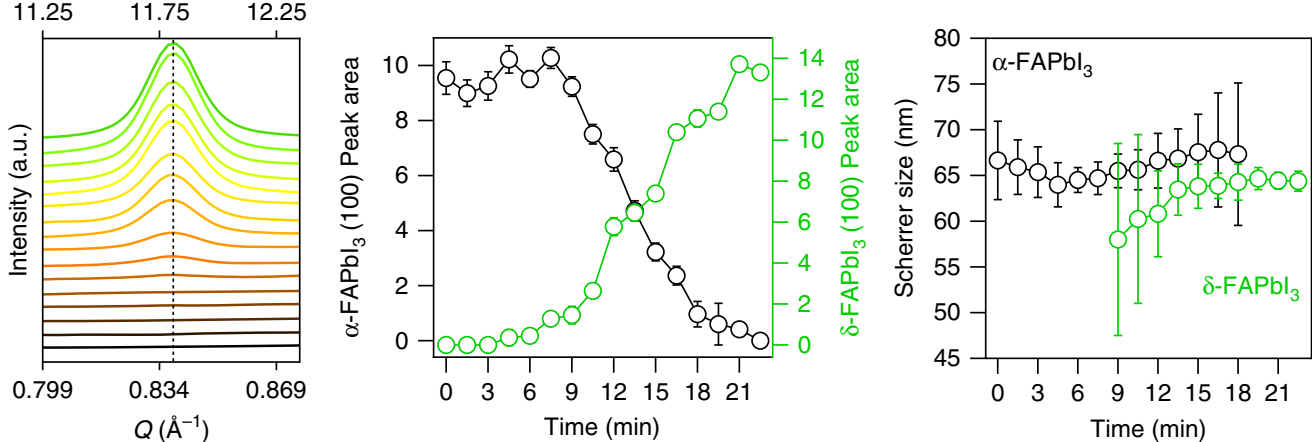

Fig. 4 Structural evolution during reversible hygrochromic cycling. a In-situ wide-angle $X$-ray scattering (WAXS) data collected on a $F A_{n+1} P b_{n} l_{3 n+1}$ composite film over three cycles of alternating exposure to $82 \%$ relative humidity (RH) and He flow. b Select WAXS data extracted from (a). Zoom-in on the region corresponding to the (100) peak of cubic $\alpha-\mathrm{FAPbl}_{3}$ (c) and to the (100) peak of hexagonal $\delta$ - $\mathrm{FAPbl}$ ( $(\mathbf{d})$. The $2 \theta$ axes are relative to $\mathrm{Cu} \mathrm{K} \alpha$ $(1.5406 \AA, 8.04 \mathrm{eV})$ radiation and was calculated from $Q=4 \pi \sin (\theta) / \lambda$ where $\lambda$ is the excitation wavelength. The WAXS background scattering is caused by the $\mathrm{Al}_{2} \mathrm{O}_{3}$ scaffold and glass substrate, which is necessary for chromic properties as discussed in Supplementary Note 2. Comparison of cubic $\alpha$-FAPbl 3 (100) and hexagonal $\delta$ - $\mathrm{FAPbl}_{3}(100)$ peak area (e) and Scherrer crystallite size (f) as a function of time exposed to $82 \%$ RH. Fits and s.d. error bars in (e, $\mathbf{f}$ ) were obtained by fitting the cubic $\alpha-\mathrm{FAPb}_{3}$ or hexagonal $\delta$ - $\mathrm{FAPbl}_{3}(100)$ peaks in (b) to a Voigt function. 
Surface energy and strain are known to stabilize small or 2D grains of $\alpha-\mathrm{FAPbI}_{3}$, whereas bulk crystals thermodynamically favor the non-perovskite $\delta-\mathrm{FAPbI}_{3}$ hexagonal phases ${ }^{34,53}$. The strain of the domains is reduced as the domain grows and eventually transforms into the thermodynamically favored $\delta-\mathrm{FAPbI}_{3}$ phase. We observe a strain-induced shift in the (100) peak of $\alpha$-FAPbI ${ }_{3}$ from $0.995 \AA^{-1}$ to $0.991 \AA^{-1}\left(\Delta=0.004 \AA^{-1}\right)$ as $\mathrm{RH}$ is increased due to a relaxation of the growing $\alpha-\mathrm{FAPbI}_{3}$ crystal between FAI layers (Fig. $4 \mathrm{c})^{34}$. In contrast to the (100) peak of $\alpha-\mathrm{FAPbI}_{3}$ at $0.995 \AA^{-1}$, the (100) peak of $\delta$-FAPbI ${ }_{3}$ at $0.838 \AA^{-1}$ does not exhibit a shift in $Q$ due to the relatively nonexistent strain in the $1 D$ $\delta$ - $\mathrm{FAPbI}_{3}$ lattice (Fig. $\left.4 \mathrm{~d}\right)^{34}$. We note that the $\delta$ - $\mathrm{FAPbBr}_{3}$ phase is not observed at high RH (Supplementary Fig. 14) because $\delta$-FAPbBr 3 is only stable below $-8^{\circ} \mathrm{C}(265 \mathrm{~K})^{54}$.

The WAXS data clearly shows hygrochromism in composite $\mathrm{FA}_{\mathrm{n}+1} \mathrm{~Pb}_{\mathrm{n}} \mathrm{I}_{3 \mathrm{n}+1}$ films is not due to recrystallization of the material (dissolution of one phase followed by precipitation of another), but rather by reversible FAI shuttling between grains that maintain their initial size. We tracked the evolution of the (100) peak area for each species as a function of time exposed $82 \% \mathrm{RH}$ (Fig. 4e) and quantified the size of the $\mathrm{FA}_{\mathrm{n}+1} \mathrm{~Pb}_{\mathrm{n}} \mathrm{I}_{3 \mathrm{n}+1}$ domains using Scherrer analysis (Fig. $4 \mathrm{f})^{55}$. The $\alpha-\mathrm{FAPbI}_{3}$ (100) peak area decreases while the $\delta-\mathrm{FAPbI}_{3}(100)$ peak area increases with an intersection occurring between $12-15 \mathrm{~min}$, indicating the transformation of a single grain rather than the formation of a new one. $2 \mathrm{D}$ WAXS data collected during phase evolution shows the grains are polycrystalline and do not become textured over time (Supplementary Fig. 15), and the size of the domains remain constant as the $\mathrm{FA}_{\mathrm{n}+1} \mathrm{~Pb}_{\mathrm{n}} \mathrm{I}_{3 \mathrm{n}+1}$ domains evolve with increasing $\mathrm{RH}$ (Fig. $4 \mathrm{f}$ ). After exposure to flowing humid air at $82 \% \mathrm{RH}$ until the film is white/colorless, exposure of flowing dry He reverses the observed phase transformations: the (100) peak of $\delta$ - $\mathrm{FAPbI}_{3}$ at $0.838 \AA^{-1}$ disappears while the (100) peak of $\alpha-\mathrm{FAPbI}_{3}$ at $0.995 \AA^{-1}$, and the (001), (002), (201), and (003) peaks of $\mathrm{FA}_{2} \mathrm{PbI}_{4}$ at $0.703 \AA^{-1}$, $1.400 \AA^{-1}, 2.040 \AA^{-1}$, and $2.095 \AA^{-1}$ reemerge (Fig. 4a). As we remove $\mathrm{H}_{2} \mathrm{O}$ from the film, FAI is re-inserted into the $\alpha / \delta-\mathrm{FAPbI}_{3}$ domains to re-form the layered $\mathrm{FA}_{\mathrm{n}+1} \mathrm{~Pb}_{\mathrm{n}} \mathrm{I}_{3 \mathrm{n}+1}$ structure.

Dynamic control of optoelectronic properties. Optical spectroscopy is used to probe the optical properties of the $\mathrm{FA}_{\mathrm{n}+1} \mathrm{~Pb}_{\mathrm{n}} \mathrm{I}_{3 \mathrm{n}+1}$ domains as the $n=1$ material coalesces to higher dimensional structures $(n>1)$. Our optical absorption and photoluminescence (PL) data confirm each observed color is a $\mathrm{FA}_{n+1} \mathrm{~Pb}_{\mathrm{n}} \mathrm{I}_{3 \mathrm{n}+1}$ mixture with multiple thicknesses that span $n=1$ to $n=\infty$ (Fig. 5a). Varying the $\mathrm{RH}$ changes the relative ratios of $n$ as the $\mathrm{FA}_{\mathrm{n}+1} \mathrm{~Pb}_{\mathrm{n}} \mathrm{I}_{3 \mathrm{n}+1}$ domains trend toward thicker layers with increasing RH. Increasing the $\mathrm{RH}$ up to $78 \%$ results in a decrease of the excitonic peak at $2.79 \mathrm{eV}$ and an increase in the absorption edge at $2.51 \mathrm{eV}$ as well as the emergence of new absorption edges located at $2.30 \mathrm{eV}, 2.07 \mathrm{eV}$, and $1.77 \mathrm{eV}$ (Fig. 5a). Subjecting the film to $80 \%$ RH causes a decrease in all peaks as the film transforms to white/ colorless. A dramatic absorption change is observed upon reaching $82 \% \mathrm{RH}$ in which absorbance in the visible region is greatly reduced and a strong absorbance peak located at $3.18 \mathrm{eV}$ emerges that is consistent with formation of hexagonal $\delta$-FAPbI ${ }_{3}{ }^{28,56}$. This large distribution of absorption properties obtainable by varying RH is reflected in the CIE $1976 \mathrm{~L}^{*} \mathrm{a}^{*} \mathrm{~b}^{*}$ coordinate space that is representative of the human perception of color (Fig. 5b).

Discrete optical transitions observed in the absorbance spectra occur due to the separation or coalescence of $2 \mathrm{D}$ octahedra layers. The optical bandgap of $2 \mathrm{D} \mathrm{FA}_{\mathrm{n}+1} \mathrm{~Pb}_{\mathrm{n}} \mathrm{I}_{3 \mathrm{n}+1}$ materials increases monotonically as $n$ approaches 1 due to formation of minibands in the quantum well superlattice structure that emerges from alternating layers of formamidinium and connected lead halide octahedra layers (Fig. 6a). The optical bandgap increase relative to $3 \mathrm{D} \alpha-\mathrm{FAPbI}_{3}$ is written as:

$$
E_{\mathrm{g}, 2 \mathrm{D}}=E_{\mathrm{g}, 3 \mathrm{D}}+E_{\mathrm{e}}+E_{\mathrm{h}}
$$

where $E_{\mathrm{g}, 3 \mathrm{D}}=1.52 \mathrm{eV}$ is the bulk bandgap of $\alpha-\mathrm{FAPbI}_{3}{ }^{57}$ and $E_{\mathrm{e}(\mathrm{h})}$ is the minimum energy of the lowest-energy miniband. We determine $E_{\mathrm{e}(\mathrm{h})}$ by adapting the Kronig-Penney (KP) model ${ }^{58}$ for an electron (hole) in a one-dimensional periodic potential. The KP-like model has successfully described conventional III-V superlattice structures ${ }^{59,60}$ and has recently been applied to MHP materials ${ }^{61-63}$. The dispersion relation for electrons (holes) in the $x$ direction is:

$$
\cos \left(\beta L_{\mathrm{qw}}\right) \cosh \left(\alpha L_{\mathrm{b}}\right)+\frac{1}{2}\left(\gamma-\gamma^{-1}\right) \sin \left(\beta L_{\mathrm{qw}}\right) \sinh \left(\alpha L_{\mathrm{b}}\right)=\cos \left(\mathbf{k}\left(L_{\mathrm{qw}}+L_{\mathrm{b}}\right)\right)
$$

where $L_{\mathrm{qw}}$ is the width of the metal halide quantum well layer, and $L_{\mathrm{b}}$ is the width of the barrier layer composed of formamidinium. Both widths are determined from XRD studies $\left(L_{\mathrm{qw}}=0.624 \mathrm{~nm}\right.$ and $\left.L_{\mathrm{b}}=0.690 \mathrm{~nm}\right) . \mathbf{k}$ is the superlattice wavevector, which is bound by $-\pi\left(L_{\mathrm{qw}}+L_{\mathrm{b}}\right)$ and $\pi\left(L_{\mathrm{qw}}+L_{\mathrm{b}}\right)$. The minimum energy of the lowest-energy miniband occurs when $\mathbf{k}=0$. For simplicity, we define: $\beta^{2}=2 m_{\mathrm{qw}, \mathrm{e}(\mathrm{h})} E_{e(\mathrm{~h})} \hbar^{-2}$ and $\alpha^{2}=2 m_{\mathrm{b}, \mathrm{e}(\mathrm{h})}\left(V_{\mathrm{e}(\mathrm{h})}-E_{\mathrm{e}(\mathrm{h})}\right) \hbar^{-2}$. The effective masses of electrons and holes are assumed to be the same for the quantum well $\left(m_{\mathrm{qw}}=m_{\mathrm{qw}, \mathrm{e}}=m_{\mathrm{qw}, \mathrm{h}}\right)$ and barrier

b

a

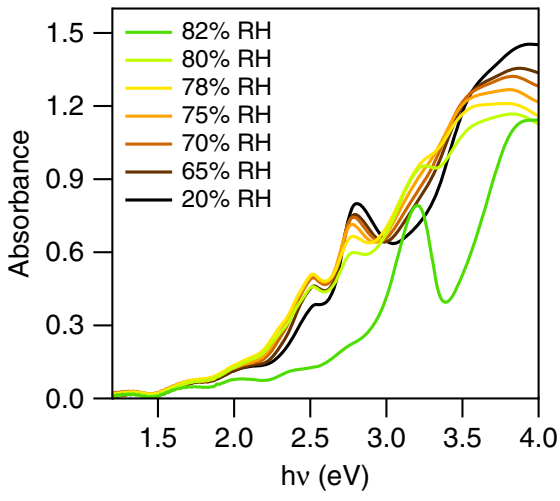

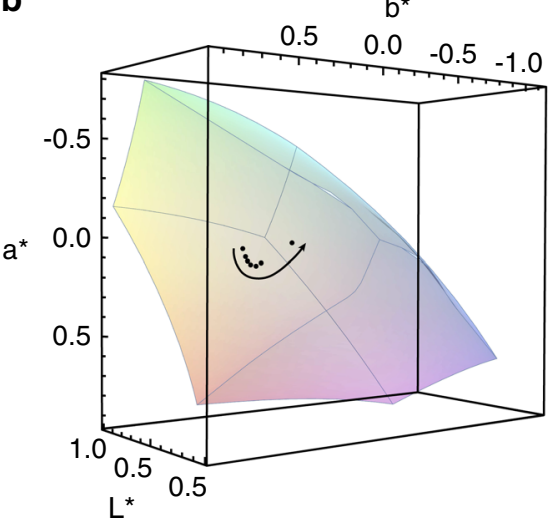

Fig. 5 Color of hygrochromic films. a Absorbance and $\mathbf{b}$ Color of $\left.F A_{n+1} P_{n}\right|_{3 n+1}$ composite films plotted in CIE $1976 L^{\star} a^{\star} b^{\star}$ coordinate space. Film color is calculated from absorbance spectra in (a). The colored polyhedron in $\mathbf{b}$ is a visualization of the sRGB gamut used in displays and digital photography. The arrow in $\mathbf{b}$ shows the direction of increasing relative humidity $(\mathrm{RH})$. 

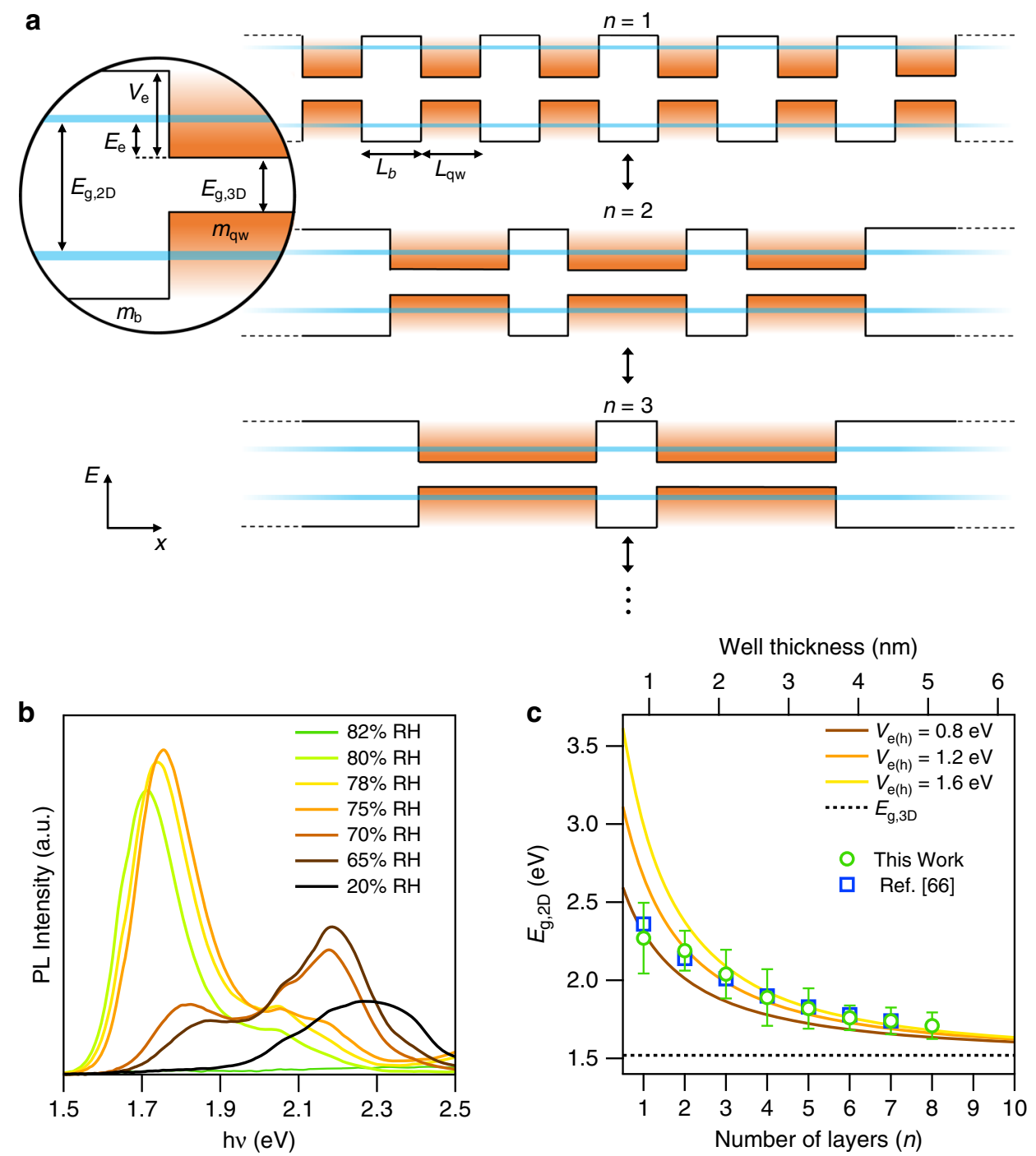

Fig. 6 Superlattice description of $\mathbf{F A}_{\mathbf{n}+\mathbf{1}} \mathbf{P b}_{\mathbf{n}} \mathbf{I}_{\mathbf{3 n + 1}}$ optical properties. a Diagram of the Kronig-Penney-like model used to describe $F A_{n+1} P b_{n} I_{3 n+1}$ optical properties. b Photoluminescence (PL) of hygrochromic $\left.\mathrm{FA}_{n+1} \mathrm{~Pb}_{n}\right|_{3 n+1}$ films collected at various relative humidity (RH). Each spectrum exhibits multiple peaks due to a mixture of ' $n$ ' layers. c A plot of the peak PL position and models used to describe our PL data. Marker position corresponds to the peak of the PL spectra in (b), and the error bars are the full-width at half maximum of the peak. Model parameters are described in the text.

$\left(m_{\mathrm{b}}=m_{b, \mathrm{e}}=m_{\mathrm{b}, \mathrm{h}}\right)$. We apply literature values for the effective mass in the metal halide layer ${ }^{57}\left(m_{\mathrm{qw}}=0.1 m_{0}\right.$, where $m_{0}$ is the rest mass of an electron) and the barrier layer ${ }^{64}\left(m_{\mathrm{b}}=m_{\mathrm{qw}} / 0.4\right)$. The barrier height $\left(V_{\mathrm{e}(\mathrm{h})}\right)$ for the electrons (holes) is an expression of the bandgap of the formamidinium layers that separate metal halide layers. For simplicity, we assume $V_{\mathrm{e}}=V_{\mathrm{h}}$. The expression for $\gamma$ is modified from the classic KP model $(\gamma=\alpha / \beta)$ to take into account the difference in effective mass of the electrons (holes) in the quantum well and barrier layers: $\gamma=\alpha m_{\mathrm{qw}, \mathrm{e}(\mathrm{h})} / \beta m_{\mathrm{b}, \mathrm{e}(\mathrm{h})}$.

PL shows discrete miniband transitions from the optical bandgaps of a mixture of $\mathrm{FA}_{\mathrm{n}+1} \mathrm{~Pb}_{\mathrm{n}} \mathrm{I}_{3 \mathrm{n}+1}$ thicknesses $(n)$ that increase as the $\mathrm{RH}$ increases (Fig. $6 \mathrm{~b}$ ). As the $\mathrm{RH}$ increases to $80 \%$, the PL peak shifts from $2.28 \mathrm{eV}$ to $1.71 \mathrm{eV}$. It is notable that the PL is tuned in the visible region over a $0.56 \mathrm{eV}$ window by simply varying the RH. The PL is quenched upon reaching $82 \%$ $\mathrm{RH}$, which is consistent with the transition to $\delta$-FAPbI ${ }_{3}^{28}$. We successfully reproduce our experimental PL by numerically solving Eq. 2 for $E_{\mathrm{e}(\mathrm{h})}$ to produce $E_{\mathrm{g}, 2 \mathrm{D}}$ as a function of quantum well width $\left(L_{\mathrm{qw}}\right)$ (Fig. $6 \mathrm{c}$ ). The thickness of a monolayer in $\mathrm{FA}_{\mathrm{n}+1} \mathrm{~Pb}_{\mathrm{n}} \mathrm{I}_{3 \mathrm{n}+1}$ is $0.624 \mathrm{~nm}$. The KP-like model nicely reproduces our optical bandgap data determined from PL measurements for $n>2$. A potential barrier height of $V_{\mathrm{e}(\mathrm{h})}=1.2 \mathrm{eV}$ best fits the data, which is a reasonable bandgap for a FAI salt layer $\left(E_{\mathrm{g}, \mathrm{FAX}}=E_{\mathrm{g}, 3 \mathrm{D}}+e\left(V_{\mathrm{e}}+V_{\mathrm{h}}\right)=3.92 \mathrm{eV}\right)$ between the lead halide sheets. The data is captured by varying the barrier height between 0.8 and $1.6 \mathrm{eV}$. We posit the barrier height will be affected by the presence of water vapor interacting with the system. The model is also in good agreement with previous work on layered MHP materials, where butyl groups separate methylammonium lead halide layers ${ }^{43}$. The monolayer $(n=1)$ case is not described well by our model, in addition to data from Kanatzitis ${ }^{43,65}$ and others $^{66}$. The deviation is known to occur due to the increasing dielectric confinement, which increases the exciton binding energy in $n=1$ materials ${ }^{67-69}$. Intuitively, the bandgap of a lead iodide monolayer is no longer represented well by the bulk properties of $\alpha-\mathrm{FAPbI}_{3}$.

We expect sizable differences in the photoconductivity of each phase as the $\mathrm{FA}_{\mathrm{n}+1} \mathrm{~Pb}_{\mathrm{n}} \mathrm{I}_{3 \mathrm{n}+1}$ grains transition between $2 \mathrm{D} \mathrm{FA} n+1$ $\mathrm{Pb}_{\mathrm{n}} \mathrm{I}_{3 \mathrm{n}+1}, 3 \mathrm{D} a-\mathrm{FAPbI}_{3}$, and $1 \mathrm{D} \delta-\mathrm{FAPbI}_{3}$ based on differences in excitonic character and binding energy. We measure these differences using contactless flash-photolysis time-resolved microwave conductivity (fp-TRMC) ${ }^{70,71}$ by photoexciting composite 
Table 1 Average $\phi \Sigma \mu$ values measured by fp-TRMC at $450 \mathrm{~nm}$.

\begin{tabular}{llll}
$\mathbf{R H}(\%)$ & Color & $\boldsymbol{n}$ & $\boldsymbol{\phi \Sigma} \boldsymbol{\mu}\left(\mathbf{c m}^{\mathbf{2}} \mathbf{V}^{-\mathbf{1}} \mathbf{s}^{-\mathbf{1}}\right)$ \\
\hline $20 \pm 3$ & Yellow & $1-2$ & $0.003 \pm 0.002$ \\
$70 \pm 3$ & Orange & $2-4$ & $0.014 \pm 0.002$ \\
$78 \pm 3$ & Brown & $>4$ & $0.019 \pm 0.008$ \\
\hline
\end{tabular}

$\mathrm{FA}_{\mathrm{n}+1} \mathrm{~Pb}_{\mathrm{n}} \mathrm{I}_{3 \mathrm{n}+1}$ films at $450 \mathrm{~nm}$ and at the lowest possible laser fluences ( $\mathrm{ca}$. $10^{11}-10^{12}$ photons $\mathrm{cm}^{-2}$ ) to obtain satisfactory signal-to-noise while avoiding higher-order recombination effects associated with high charge densities (Supplementary Fig. 16). Indeed, we observe a significant change in the yield-mobility product $(\phi \Sigma \mu)$ when comparing films exposed to $20 \% \mathrm{RH}$ (yellow) and those to $70-78 \% \mathrm{RH}$ (orange and brown). The orange and brown phases demonstrate $c a$. 5-6 times higher $\phi \Sigma \mu$ values compared to the yellow phase (Table 1, Supplementary Table 1), which is likely due in part to increases in charge yield $(\phi)$ as the exciton binding energy decreases for more 3D connected (higher n) domains. We believe electron and hole mobilities (represented by $\Sigma \mu$ ) increase concomitantly with charge yield ${ }^{72}$ and argue the $\phi \Sigma \mu$ values of the orange phase are closer to the brown phase likely due to an appreciable density of $n>4$ domains that dominate the fp-TRMC signal over smaller $(n=1-3)$ layers. Putting limits on the sum of the hole and electron mobilities for these compounds, we estimate that values of $0.003-0.3$ and $0.019-1.9 \mathrm{~cm}^{2} \mathrm{~V}^{-1} \mathrm{~s}^{-1}$ are possible for yellow and brown phases, respectively, assuming charge yields between 100 and $1 \%$.

$\phi \Sigma \mu$ values obtained for the brown (most photoconductive) phase were comparable to those obtained in other works. $(\mathrm{BA})_{2}(\mathrm{MA})_{\mathrm{n}-1} \mathrm{~Pb}_{\mathrm{n}} \mathrm{I}_{3 \mathrm{n}+1}(n=3-4)$ was measured to have $\phi \Sigma \mu=$ $0.03-0.04 \mathrm{~cm}^{2} \mathrm{~V}^{-1} \mathrm{~s}^{-1} 73$. However, these films were measured at up to 2 orders of magnitude higher fluence $\left(c a .10^{13}\right.$ photons $\mathrm{cm}^{-2}$ ) than the $\mathrm{FA}_{\mathrm{n}+1} \mathrm{~Pb}_{\mathrm{n}} \mathrm{I}_{3 \mathrm{n}+1}$ composite films measured here ( $c a .10^{11}$ photons $\mathrm{cm}^{-2}$ ). As such, the values for BA-based 2D RuddlesdenPopper MHPs obtained from that work are likely higher than reported since the low fluence regimes, where $\phi \Sigma \mu$ values exhibit little-to-no fluence-dependence, were not measured. Indeed fpTRMC measurements on $(\mathrm{BA})_{2}(\mathrm{MA})_{\mathrm{n}-1} \mathrm{~Pb}_{\mathrm{n}} \mathrm{I}_{3 \mathrm{n}+1} \quad(\mathrm{n}=4-5)$ by Gélvez-Rueda et al. ${ }^{72}$ at fluences similar to this work demonstrated $\phi \Sigma \mu$ values $c a .10-30 \mathrm{~cm}^{2} \mathrm{~V}^{-1} \mathrm{~s}^{-1}$, over three orders of magnitude larger than the $\mathrm{FA}_{\mathrm{n}+1} \mathrm{~Pb}_{\mathrm{n}} \mathrm{I}_{3 \mathrm{n}+1}$ MHPs studied here. Measurements on $(\mathrm{MA})_{2} \mathrm{~Pb}(\mathrm{SCN})_{2} \mathrm{I}_{2}(n=1)^{74}$ and (BPEA $)_{2}(\mathrm{MA}) \mathrm{Pb}_{2} \mathrm{I}_{7}(n=2)^{75}$ yield $\phi \Sigma \mu$ values $c a .1 \mathrm{~cm}^{2} \mathrm{~V}^{-1} \mathrm{~s}^{-1}$ which is ca. 50 times greater than $\mathrm{FA}_{\mathrm{n}+1} \mathrm{~Pb}_{\mathrm{n}} \mathrm{I}_{3 \mathrm{n}+1}$. A less dramatic difference was found when comparing the range of amplitude-weighted average free charge lifetimes measured for the brown phase (ca. 20-90 ns) to (MA) $)_{2} \mathrm{~Pb}$ $(\mathrm{SCN})_{2} \mathrm{I}_{2}(n=1, c a .100 \mathrm{~ns})^{74}$ and $(\mathrm{BA})_{2}(\mathrm{MA})_{\mathrm{n}-1} \mathrm{~Pb}_{\mathrm{n}} \mathrm{I}_{3 \mathrm{n}+1}(n=4-5$, ca. $100-200 \mathrm{~ns})^{72}$. Our scaffold-impregnated films likely have random crystallite orientation, which will lower our $\phi \Sigma \mu$ values relative to some of the literature discussed here ${ }^{73}$. Only free charges within crystallites oriented parallel to our linearly polarized microwave probe will absorb appreciably. The variation of free charge lifetimes (and to some degree $\phi \Sigma \mu$ ) for the brown phase on a film-to-film basis could be due to differences in the density of crystallites and crystallite size distribution based on modest differences in film processing conditions, such as scaffold thickness and $\mathrm{Al}_{2} \mathrm{O}_{3}$ nanoparticle size dispersity used in the scaffold. We were not able to measure $\phi \Sigma \mu$ values of the white/colorless phase, as the lowest fluences were sufficient to convert this phase into the brown phase via heat-induced dehydration mechanism (Supplementary Fig. 17) that we have observed at temperatures as low as $35^{\circ} \mathrm{C}$ (Supplementary Fig. 12).

\section{Discussion}

We synthesized layered FA-based MHPs of the general formula $\mathrm{FA}_{\mathrm{n}+1} \mathrm{~Pb}_{\mathrm{n}} \mathrm{X}_{3 \mathrm{n}+1}(\mathrm{X}=\mathrm{I}, \mathrm{Br})$ and their mixed-halide compositions and show reversible multicolor chromism based on two different stimuli: solvent vapor and temperature. We design composite $\mathrm{FA}_{\mathrm{n}+1} \mathrm{~Pb}_{\mathrm{n}} \mathrm{X}_{3 \mathrm{n}+1}$ films by synthesizing $\mathrm{FA}_{\mathrm{n}+1} \mathrm{~Pb}_{\mathrm{n}} \mathrm{X}_{3 \mathrm{n}+1}$ domains adjacent to a FAX "reservoir" composed of excess FAX salt that allows FAX salt pairs to shuttle between $\mathrm{FA}_{\mathrm{n}+1} \mathrm{~Pb}_{\mathrm{n}} \mathrm{X}_{3 \mathrm{n}+1}$ domains and the FAX reservoir. The interactions between each species results in a structural equilibrium between $2 \mathrm{D} \mathrm{FA}_{n+1} \mathrm{~Pb}_{\mathrm{n}} \mathrm{X}_{3 \mathrm{n}+1}$ layers, 3D $\alpha-\mathrm{FAPbX}_{3}$ domains, and $1 \mathrm{D} \delta$ - $-\mathrm{FAPbI}_{3}$ domains that can be controlled through modulating the strength and number of H-bonds between the reservoir, MHP, and solvent vapor. Unlike previously reported chromic MHPs that only switch between a single dark and a single transparent phase, these films reversibly switch between multiple colors including yellow, orange, red, brown, and white/colorless. The optical transitions are captured by a Kronig-Penney-like model that describes photoluminescence of the material as metal halide octahedra layers separate and coalesce into superlattices of varied thickness. Our work will enable a new generation of functional materials that couple tunable and reversible chromism with the extraordinary optoelectronic properties of MHP materials.

\section{Methods}

Materials. Aluminum oxide nanoparticles $\left(\mathrm{Al}_{2} \mathrm{O}_{3},<50 \mathrm{~nm}\right.$ particle size, $20 \mathrm{wt} \%$ in isopropanol) and dimethyl sulfoxide (DMSO, anhydrous, $\geq 99.9 \%$ ) were purchased from Sigma-Aldrich; lead(II) iodide $\left(\mathrm{PbI}_{2}, 99.99 \%\right)$ from TCI; formamidinium iodide (FAI) from GreatCell Solar Materials.

$\mathbf{F A}_{\mathbf{2}} \mathrm{Pbl}_{\mathbf{4}}$ powder preparation. Powders were prepared by weighing a 4:1 molar ratio of $\mathrm{FAI}: \mathrm{PbI}_{2}$ in a nitrogen glovebox, sealing in a hardened stainless-steel vial, then ball-milling in a SPEX high energy ball mill for 60 minutes. The vial was then transferred back to the glovebox for recovery of the milled powders. Powders were not exposed to air/humidity until hygrochromic tests were conducted.

$\mathbf{F A}_{\mathbf{n}+\mathbf{1}} \mathbf{P b}_{\mathbf{n}} \mathbf{X}_{\mathbf{3 n + 1}}$ composite film preparation. Glass substrates $(25 \mathrm{~mm} \times 25 \mathrm{~mm} \times$ $1 \mathrm{~mm}$ ) were sonicated in isopropanol (IPA) for $10 \mathrm{~min}$ and blown dry with $\mathrm{N}_{2}$. The substrates were then treated in a UV-ozone cleaner for $10 \mathrm{~min}$ before spin-coating $200 \mu \mathrm{L}$ of $16 \mathrm{wt} \% \mathrm{Al}_{2} \mathrm{O}_{3}$ nanoparticles $(20-40 \mathrm{~nm})$ in IPA at $3000 \mathrm{rpm}$ for $30 \mathrm{~s}$. The resulting film was annealed at $150{ }^{\circ} \mathrm{C}$ for $5 \mathrm{~min}$ followed by $500^{\circ} \mathrm{C}$ for $25 \mathrm{~min}$. This process yielded a $1.58 \pm 0.02 \mu$ m-thick $\mathrm{Al}_{2} \mathrm{O}_{3}$ scaffold. The $\mathrm{Al}_{2} \mathrm{O}_{3} \mathrm{NP}$ precursor can be diluted with IPA to yield thinner films as shown in Supplementary Fig. 18. Next, $75 \mu \mathrm{L}$ of a precursor solution containing $3 \mathrm{M} \mathrm{FAX}$ and $0.75 \mathrm{M} \mathrm{PbX}_{2}\left(4: 1\right.$ FAX:PbX $\left.\mathrm{Pb}_{2}\right)$ in DMSO was spin-coated at $4000 \mathrm{rpm}$ for $30 \mathrm{~s}$ followed by annealing at $60^{\circ} \mathrm{C}$ for $10 \mathrm{~min}$. We note here that precursor concentration must be optimized for a given scaffold thickness. Optimal precursor concentrations based on $\mathrm{PbX}_{2}([\mathrm{FAX}]=$ $\left.4\left[\mathrm{PbX}_{2}\right]\right)$ for a given scaffold thickness are as follows: $0.7-1 \mathrm{M} \mathrm{PbX}_{2}$ for $1.0-1.6 \mu \mathrm{m}$ thick, 0.4-0.6 $\mathrm{M} \mathrm{PbX}_{2}$ for $600-1000 \mathrm{~nm}$ thick, and 0.3-0.4 $\mathrm{M} \mathrm{PbX}_{2}$ for $300-600 \mathrm{~nm}$ thick. Both spin-coating and annealing were performed in air while maintaining the relative humidity $(\mathrm{RH})$ between 40 and $45 \%$. The substrates were stored in a drawer $(<20 \% \mathrm{RH})$ or desiccator in air until needed. See Supplementary Note 2 for a discussion on the impact of processing conditions on composite $\mathrm{FA}_{\mathrm{n}+1} \mathrm{~Pb}_{\mathrm{n}} \mathrm{X}_{3 \mathrm{n}+1}$ film formation.

Humidity control. Humidy-controlled experiments were performed in a glovebox equipped with a humidity controller connected to a humidity sensor (error of \pm $3 \%$ ), humidifier, and dehumidifier unless noted elsewhere. The controller maintains the humidity with an accuracy of $\pm 0.1-0.3 \%$ The humidity controller was calibrated to saturated $\mathrm{KBr}$ in water, which exhibits a relative humidity (RH) of $81.67 \pm 0.21 \%$ at $20^{\circ} \mathrm{C}^{76}$. We reported $\mathrm{RH}$ throughout this study; however, $\mathrm{RH}$ is different at sea level compared to high altitudes (NREL, Golden, CO, this study). We converted the RH's reported in this study to absolute humidities (AH's) using $25^{\circ} \mathrm{C}$ and $630 \mathrm{mmHg}$ as a typical barometric pressure of NREL in Golden, CO (Supplementary Table 2).

Optical characterization. Absorbance was collected with a photodiode array Hewlett-Packard $8453 \mathrm{UV}$-vis spectrometer with $\mathrm{Al}_{2} \mathrm{O}_{3}$ scaffold and glass absorbance subtracted from all spectra. Steady-state PL measurements were taken using a home-built system. Samples were excited using a Thorlabs fiber-coupled $405 \mathrm{~nm}$ light-emitting diode (LED) pulsed at $10 \mathrm{~Hz}$ using a Thorlabs DC2200 LED driver. Visible detection was made using an Ocean Optics OceanFX spectrometer. Spectra 
were stitched using a LabVIEW program developed in-house. Detector calibration was done using an Ocean Optics HL-2000-HP blackbody lamp. Prior to data acquisition, the substrate was sealed into an air-tight optical holder filled with the desired RH. Optical measurements were collected on films prepared with a $326 \pm$ $22 \mathrm{~nm}$ thick $\mathrm{Al}_{2} \mathrm{O}_{3} \mathrm{NP}$ scaffold.

Structural characterization. In situ X-ray diffraction data was collected at the Stanford Synchrotron Radiation Light Source (SSRL) at beamline 11-3. The samples were measured at an incident angle of 3 degrees and an incident X-ray wavelength of $0.9744 \AA$. A Rayonix MX225 2D detector was used to collect data, and $\mathrm{LaB}_{6}$ standard used to calibrate the data. The $\mathrm{RH}$ in the sample chamber was alternated between $35 \%$ and $82 \%$ RH using a commercial room humidifier powered by a humidity controller, which was connected to a humidity sensor within the sample chamber. The humidity in the sample chamber was reduced by flowing helium gas through the chamber. Once $35 \% \mathrm{RH}$ was reached, the humidity was increased by manually reducing the He flow until the humidity stabilized at $82 \%$ RH. The data collection were continuous except for brief interruptions for changing the sample chamber connection between the humidifier and the He. The integration time per measurement was $30 \mathrm{~s}$. The data was integrated using GSAS$\mathrm{II}^{77} .2 \theta$ values were calculated by converting $Q$ data relative to $\mathrm{Cu} \mathrm{Ka}(1.5406 \AA$, $8.04 \mathrm{eV}$ ). Scherrer analysis was performed using a $\kappa$ value of 0.9 and FWHM values with error bars obtained by fitting peaks to a Voigt function. Non-synchrotron WAXS of composite films was collected in air using a Bruker D8 Discover diffractometer with GADDS 4-circle detector (General Area Detector Diffraction System) and $\mathrm{Cu} \mathrm{Ka}(1.5406 \AA, 8.04 \mathrm{eV})$ radiation. WAXS of powder was collected in air using a Rigaku Smartlab diffractometer using $\mathrm{Cu} \mathrm{Ka}(1.5406 \AA ̊ .8 .04 \mathrm{eV})$ radiation. Fast scans (ca. $2 \mathrm{~min}$ ) were done before and after a long scan (ca. $30 \mathrm{~min}$ ) to verify no change in the material due to beam exposure. Interlayer spacing of butylammonium, phenylethylammonium, and hexylammonium was calculated using Jmol by performing an energy minimization of the molecule, measuring the longest hydrogen-hydrogen distance, and then multiplying this distance by 2 based on the assumption that the interlayer spacing is composed of two end-to-end molecules.

DRIFTS measurements. A Bruker Alpha FTIR spectrometer outfitted with a diffuse-reflectance infrared Fourier transform spectroscopy (DRIFTS) attachment was used in the study, and all measurements were performed in a humidity glovebox as described above. Samples were prepared as described above except $\mathrm{Au}$ coated $\mathrm{Si}$ was used instead of glass as the substrate. DRIFTS data were collected between 350 and $4000 \mathrm{~cm}^{-1}$ with a resolution of $2 \mathrm{~cm}^{-1}$ and was atmosphere corrected. RH and temperature data were collected using a data logger with points collected every second. Each DRIFTS spectrum was collected over 45 s, so 45 individual $\mathrm{RH}$ and temperature points were averaged to determine the average $\mathrm{RH}$ and temperature of each spectrum. The RH was increased at a rate of $3.2 \pm 0.2 \%$ $\mathrm{min}^{-1}$ and decreased at a rate of $1.9 \pm 0.3 \% \mathrm{~min}^{-1}$ during data acquisition.

fp-TRMC measurements. Our flash-photolysis time-resolved microwave conductivity (fp-TRMC) measurement system and methods has been described in detail elsewhere ${ }^{70,71}$. Photoexcitation was accomplished using a Nd:YAG (Spectraphysics Quanta Ray SP Pro 230-30H) laser with $9 \mathrm{~W}$ of $355 \mathrm{~nm}$ at $30 \mathrm{~Hz}$ to pump an OPO (Spectraphysics GWU PremiScan ULD/500) with output over the range of $410-2500 \mathrm{~nm}$ with $7 \mathrm{~ns}$ pulses (ca. $3 \mathrm{~W}$ output, varies by wavelength). Blank quartz substrates and quartz substrates with only the alumina scaffold were used to gauge any background contributions to the fp-TRMC transients and showed no appreciable response. All samples were excited at $450 \mathrm{~nm}$ with fluences in the range of $c a .1 \times 10^{11}$ to $2 \times 10^{15}$ photons $\mathrm{cm}^{-2}$ depending on the strength of the sample response and phase stability during illumination. A $399 \mathrm{~nm}$ long pass filter and $700 \mathrm{~nm}$ short pass filter were used to cut out residual 355 and $1064 \mathrm{~nm}$ light from the optical parametric oscillator, respectively. Maintaining the RH levels necessary to stabilize the brown phase during measurements was achieved by sealing samples in a leak-resistant microwave cavity within the humidified glovebox described previously. At higher fluences, phases held at higher RH tended to revert back to phases at lower ones, possibly due to heat-driven dehydration of the film (Supplementary Fig. 17). For this reason, the white/colorless phase could not be measured at even the lowest fluences. Phase purity was assessed by monitoring the steady-state photoluminescence for films in-situ during fp-TRMC measurements (e.g., see PL data in Supplementary Fig. 19) using a camera lens to focus emitted photons from the microwave cavity into an optical fiber that was coupled to a Princeton Instruments SpectraPro 2500i spectrometer with a liquid-nitrogen cooled CCD detector. A $500 \mathrm{~nm}$ long pass filter was used to filter out excitation light $(450 \mathrm{~nm})$ and photoluminescence spectra were typically acquired by averaging 60 seconds to monitor phase stability on a minute-to-minute basis during measurements. PL spectra were not corrected by a calibration lamp. The yellow phase was the only sample for which the entire fluence range was measured. Typical fluences for orange and brown samples were ca. $1-20 \times 10^{11}$ photons $/ \mathrm{cm}^{2}$. Most transients were acquired for 30,000 shots or until $\mathrm{S} / \mathrm{N}=10$. For some yellow and orange samples with lower $\mathrm{S} / \mathrm{N}$ at low fluences, up to 60,000 shots were acquired. The typical fraction of absorbed photons at $450 \mathrm{~nm}$ for yellow, orange, and brown phases were $99 \%, 99 \%$, and $96 \%$, respectively. Transient fitting was done using a custom global fitting routine in Igor Pro 8 using a biexponential fit. $\phi \Sigma \mu$ values at each fluence were extracted by summing the amplitudes of the optimized fit coefficients. For each sample, an average of $\phi \Sigma \mu$ over the lowest four-to-five fluences (i.e., regime where $\phi \Sigma \mu$ shows little-to-no fluence dependence) were taken to represent the average yield-mobility product for that sample. These values were then further averaged over three samples to obtain the values and uncertainties reported here.

\section{Data availability}

The data that support the findings of this study are available from the corresponding author upon reasonable request.

\section{Code availability}

Mathematica code used to model $\mathrm{FA}_{\mathrm{n}+1} \mathrm{~Pb}_{\mathrm{n}} \mathrm{I}_{3 \mathrm{n}+1}$ optical properties is available from the corresponding author upon reasonable request.

Received: 28 February 2020; Accepted: 23 September 2020;

Published online: 16 October 2020

\section{References}

1. Sutherland, B. R. \& Sargent, E. H. Perovskite photonic sources. Nat. Photon. 10, 295-302 (2016).

2. $\mathrm{Fu}$, Y. et al. Metal halide perovskite nanostructures for optoelectronic applications and the study of physical properties. Nat. Rev. Mater. 4, 169-188 (2019).

3. Leijtens, T., Bush, K. A., Prasanna, R. \& McGehee, M. D. Opportunities and challenges for tandem solar cells using metal halide perovskite semiconductors. Nat. Energy 3, 828-838 (2018).

4. Akkerman, Q. A., Rainò, G., Kovalenko, M. V. \& Manna, L. Genesis, challenges and opportunities for colloidal lead halide perovskite nanocrystals. Nat. Mater. 17, 394-405 (2018).

5. Tennyson, E. M., Doherty, T. A. S. \& Stranks, S. D. Heterogeneity at multiple length scales in halide perovskite semiconductors. Nat. Rev. Mater. 4, 573-587 (2019).

6. Miyata, K., Atallah, T. L. \& Zhu, X. Y. Lead halide perovskites: crystal-liquid duality, phonon glass electron crystals, and large polaron formation. Sci. Adv. 3, e1701469 (2017).

7. Zhu, H. et al. Screening in crystalline liquids protects energetic carriers in hybrid perovskites. Science 353, 1409-1413 (2016).

8. Boyd, C. C., Cheacharoen, R., Leijtens, T. \& McGehee, M. D. Understanding degradation mechanisms and improving stability of perovskite photovoltaics. Chem. Rev. 119, 3418-3451 (2019).

9. Grancini, G. \& Nazeeruddin, M. K. Dimensional tailoring of hybrid perovskites for photovoltaics. Nat. Rev. Mater. 4, 4-22 (2018).

10. Dou, B. et al. Degradation of highly alloyed metal halide perovskite precursor inks: mechanism and storage solutions. ACS Energy Lett. 3, 979-985 (2018).

11. National Renewable Energy Laboratory. Best research-cell efficiencies chart, https://www.nrel.gov/pv/assets/pdfs/best-research-cell-efficiencies.20200803. pdf (2020).

12. Mitzi, D. B. In Progress in Inorganic Chemistry (ed. Kenneth D. Karlin), 1-121 (1999).

13. Saparov, B. \& Mitzi, D. B. Organic-inorganic perovskites: structural versatility for functional materials design. Chem. Rev. 116, 4558-4596 (2016).

14. Gao, Y. et al. Molecular engineering of organic-inorganic hybrid perovskites quantum wells. Nat. Chem. 11, 1151-1157 (2019).

15. Gao, X. et al. Ruddlesden-Popper perovskites: synthesis and optical properties for optoelectronic applications. Adv. Sci. 6, 1900941 (2019).

16. Mao, L. et al. Hybrid Dion-Jacobson 2D lead iodide perovskites. J. Am. Chem. Soc. 140, 3775-3783 (2018)

17. Ahmad, S. et al. Dion-Jacobson phase 2D layered perovskites for solar cells with ultrahigh stability. Joule 3, 794-806 (2019).

18. Bamfield, P. Chromic Phenomena: Technological Applications of Colour Chemistry (Royal Society of Chemistry, London, 2018).

19. Lötzsch, D., Eberhardt, V. \& Rabe, C. Chromogenic materials. Ullmann's Ency. Indust. Chem. 1-26 (2016).

20. Lampert, C. M. Chromogenic smart materials. Mater. Today 7, 28-35 (2004)

21. Wheeler, L. M. et al. Switchable photovoltaic windows enabled by reversible photothermal complex dissociation from methylammonium lead iodide. Nat. Commun. 8, 1722 (2017).

22. Lin, J. et al. Thermochromic halide perovskite solar cells. Nat. Mater. 17, 261-267 (2018)

23. Kostopoulou, A., Kymakis, E. \& Stratakis, E. Perovskite nanostructures for photovoltaic and energy storage devices. J. Mater. Chem. A 6, 9765-9798 (2018). 
24. Yao, X. et al. Protonic solid-state electrochemical synapse for physical neural networks. Nat. Commun. 11, 3134 (2020).

25. Wheeler, L. M. \& Wheeler, V. M. Detailed balance analysis of photovoltaic windows. ACS Energy Lett. 4, 2130-2136 (2019).

26. Burger, S., Ehrenreich, M. G. \& Kieslich, G. Tolerance factors of hybrid organic-inorganic perovskites: recent improvements and current state of research. J. Mater. Chem. A 6, 21785-21793 (2018).

27. Bartel, C. J. et al. New tolerance factor to predict the stability of perovskite oxides and halides. Sci. Adv. 5, eaav0693 (2019).

28. Li, Z. et al. Stabilizing perovskite structures by tuning tolerance factor: formation of formamidinium and cesium lead iodide solid-state alloys. Chem. Mater. 28, 284-292 (2015).

29. Manser, J. S., Saidaminov, M. I., Christians, J. A., Bakr, O. M. \& Kamat, P. V. Making and breaking of lead halide perovskites. Acc. Chem. Res. 49, 330-338 (2016).

30. Quan, L. N. et al. Ligand-stabilized reduced-dimensionality perovskites. J. Am. Chem. Soc. 140, 2649-2655 (2016).

31. Wheeler, L. M., Anderson, N. C., Bliss, T. S., Hautzinger, M. P. \& Neale, N. R. Dynamic evolution of 2D layers within perovskite nanocrystals via salt pair extraction and reinsertion. J. Phys. Chem. C. 122, 14029-14038 (2018).

32. Hua, Y. et al. Ethanol induced structure reorganization of $2 \mathrm{D}$ layered perovskites $(\mathrm{OA})_{2}(\mathrm{MA})_{\mathrm{n}-1} \mathrm{~Pb}_{\mathrm{n}} \mathrm{I}_{3 \mathrm{n}+1}$. J. Lumin. 220, 116981 (2020).

33. Sharma, S. K. et al. Reversible dimensionality tuning of hybrid perovskites with humidity: visualization and application to stable solar cells. Chem. Mater. 31, 3111-3117 (2019).

34. Zheng, $X$. et al. Improved phase stability of formamidinium lead triiodide perovskite by strain relaxation. ACS Energy Lett. 1, 1014-1020 (2016).

35. Chen, Y. et al. Strain engineering and epitaxial stabilization of halide perovskites. Nature 577, 209-215 (2020).

36. Chen, T. et al. Entropy-driven structural transition and kinetic trapping in formamidinium lead iodide perovskite. Sci. Adv. 2, e1601650 (2016).

37. Fraccarollo, A., Cantatore, V., Boschetto, G., Marchese, L. \& Cossi, M. Ab initio modeling of 2D layered organohalide lead perovskites. J. Chem. Phys. 144, 164701 (2016)

38. Zhu, X. et al. Vapor-fumigation for record efficiency two-dimensional perovskite solar cells with superior stability. Energy Environ. Sci. 11, 3349-3357 (2018).

39. Shin, M. et al. Low-dimensional formamidinium lead perovskite architectures via controllable solvent intercalation. J. Mater. Chem. C. 7, 3945-3951 (2019).

40. Gratia, P. et al. The many faces of mixed ion perovskites: unraveling and understanding the crystallization process. ACS Energy Lett. 2, 2686-2693 (2017).

41. Cao, D. H., Stoumpos, C. C., Farha, O. K., Hupp, J. T. \& Kanatzidis, M. G. 2D homologous perovskites as light-absorbing materials for solar cell applications. J. Am. Chem. Soc. 137, 7843-7850 (2015).

42. Mao, L., Stoumpos, C. C. \& Kanatzidis, M. G. Two-dimensional hybrid halide perovskites: principles and promises. J. Am. Chem. Soc. 141, 1171-1190 (2019).

43. Stoumpos, C. C. et al. Ruddlesden-Popper hybrid lead iodide perovskite 2D homologous semiconductors. Chem. Mater. 28, 2852-2867 (2016).

44. Milić, J. V. et al. Supramolecular engineering for formamidinium-based layered 2D perovskite solar cells: structural complexity and dynamics revealed by solid-state NMR spectroscopy. Adv. Energy Mater. 9, 1900284 (2019).

45. Yan, J. et al. Highly oriented two-dimensional formamidinium lead iodide perovskites with a small bandgap of $1.51 \mathrm{eV}$. Mater. Chem. Front. 2, 121-128 (2018).

46. Liu, Y. et al. Self-assembly of two-dimensional perovskite nanosheet building blocks into ordered Ruddlesden-Popper perovskite phase. J. Am. Chem. Soc. 141, 13028-13032 (2019).

47. Taylor, V. C. A. et al. Investigating the role of the organic cation in formamidinium lead iodide perovskite using ultrafast spectroscopy. J. Phys. Chem. Lett. 9, 895-901 (2018).

48. Wallace, V. M., Dhumal, N. R., Zehentbauer, F. M., Kim, H. J. \& Kiefer, J. Revisiting the aqueous solutions of dimethyl sulfoxide by spectroscopy in the mid- and near-infrared: experiments and car-parrinello simulations. J. Phys. Chem. B 119, 14780-14789 (2015).

49. Chuntonov, L., Kumar, R. \& Kuroda, D. G. Non-linear infrared spectroscopy of the water bending mode: direct experimental evidence of hydration shell reorganization? Phys. Chem. Chem. Phys. 16, 13172-13181 (2014).

50. Coker, D. F., Reimers, J. R. \& Watts, R. O. The infrared absorption spectrum of water. Aust. J. Phys. 35, 623-638 (1982).

51. Liu, C., Shih, K., Gao, Y., Li, F. \& Wei, L. Dechlorinating transformation of propachlor through nucleophilic substitution by dithionite on the surface of alumina. J. Soils Sediment. 12, 724-733 (2012).

52. Joseph, J. \& Jemmis, E. D. Red-, blue-, or no-shift in hydrogen bonds: a unified explanation. J. Am. Chem. Soc. 129, 4620-4632 (2007).

53. Lee, J. W. et al. $2 \mathrm{D}$ perovskite stabilized phase-pure formamidinium perovskite solar cells. Nat. Commun. 9, 3021 (2018).
54. Keshavarz, M. et al. Tracking structural phase transitions in lead-halide perovskites by means of thermal expansion. Adv. Mater. 31, e1900521 (2019).

55. Wilson, A. J. C. \& Langford, J. I. Scherrer after sixty years: a survey and some new results in the determination of crystallite size. J. Appl. Crystallogr. 11, 102-113 (1978).

56. Zhang, Y., Kim, S.-G., Lee, D., Shin, H. \& Park, N.-G. Bifacial stamping for high efficiency perovskite solar cells. Energy Environ. Sci. 12, 308-321 (2019).

57. Galkowski, K. et al. Determination of the exciton binding energy and effective masses for methylammonium and formamidinium lead tri-halide perovskite semiconductors. Energy Environ. Sci. 9, 962-970 (2016).

58. Kronig, R. D. L. \& Penney, W. G. Quantum mechanics of electrons in crystal lattices. Proc. R. Soc. Lond., Ser. A 130, 499-513 (1931).

59. Yuh, P.-F. \& Wang, K. L. Formalism of the kronig-penney model for superlattices of variable basis. Phys. Rev. B Condens. Matter 38, 13307-13315 (1988).

60. Aly, A. E.-M. \& Nasr, A. Theoretical study of one-intermediate band quantum dot solar cell. Int. J. Photoenergy 2014, 1-10 (2014).

61. Abdullah, H. \& Kuo, D.-H. Photocatalytic performance of the $\mathrm{SiO} 2 \mathrm{sphere} / \mathrm{n}$ type TiO2/p-type CuBiS2 composite catalysts coated with different contents of Ag nanoparticles under ultraviolet and visible light irradiations. Appl. Phys. A 122, 739 (2016).

62. Silver, S., Yin, J., Li, H., Brédas, J.-L. \& Kahn, A. Characterization of the valence and conduction band levels of $\mathrm{n}=12 \mathrm{D}$ perovskites: a combined experimental and theoretical investigation. Adv. Energy Mater. 8, 1703468 (2018).

63. Sichert, J. A., Hemmerling, A., Cardenas-Daw, C., Urban, A. S. \& Feldmann, J. Tuning the optical bandgap in layered hybrid perovskites through variation of alkyl chain length. APL Mater. 7, 041116 (2019).

64. Tanaka, K. \& Kondo, T. Bandgap and exciton binding energies in lead-iodidebased natural quantum-well crystals. Sci. Technol. Adv. Mater. 4, 599-604 (2003).

65. Soe, C. M. M. et al. Structural and thermodynamic limits of layer thickness in 2D halide perovskites. Proc. Natl Acad. Sci. USA 116, 58-66 (2019).

66. Sichert, J. A. et al. Quantum size effect in organometal halide perovskite nanoplatelets. Nano Lett. 15, 6521-6527 (2015).

67. Blancon, J. C. et al. Scaling law for excitons in 2D perovskite quantum wells. Nat. Commun. 9, 2254 (2018).

68. Hong, X., Ishihara, T. \& Nurmikko, A. V. Dielectric confinement effect on excitons in PbI4-based layered semiconductors. Phys. Rev. B Condens. Matter. 45, 6961-6964 (1992).

69. Katan, C., Mercier, N. \& Even, J. Quantum and dielectric confinement effects in lower-dimensional hybrid perovskite semiconductors. Chem. Rev. 119, 3140-3192 (2019).

70. Reid, O. G. et al. Quantitative analysis of time-resolved microwave conductivity data. J. Phys. D. 50, 493002 (2017).

71. Savenije, T. J., Ferguson, A. J., Kopidakis, N. \& Rumbles, G. Revealing the dynamics of charge carriers in polymer:fullerene blends using photoinduced time-resolved microwave conductivity. J. Phys. Chem. C. 117, 24085-24103 (2013).

72. Gelvez-Rueda, M. C. et al. Interconversion between free charges and bound excitons in 2D hybrid lead halide perovskites. J. Phys. Chem. C. 121, 26566-26574 (2017).

73. Venkatesan, N. R., Labram, J. G. \& Chabinyc, M. L. Charge-carrier dynamics and crystalline texture of layered Ruddlesden-Popper hybrid lead iodide perovskite thin films. ACS Energy Lett. 3, 380-386 (2018).

74. Labram, J. G. et al. Charge transport in a two-dimensional hybrid metal halide thiocyanate compound. J. Mater. Chem. C. 5, 5930-5938 (2017).

75. Venkatesan, N. R. et al. Enhanced yield-mobility products in hybrid halide Ruddlesden-Popper compounds with aromatic ammonium spacers. Dalton Trans. 48, 14019-14026 (2019).

76. Greenspan, L. Humidity fixed points of binary saturated aqueous solutions. J. Res. Nat. Bur. Stand. A: Phys. Chem. 81 A, 89-96 (1977).

77. Toby, B. H. \& Von Dreele, R. B. GSAS-II: the genesis of a modern open-source all purpose crystallography software package. J. Appl. Crystallogr. 46, 544-549 (2013).

78. Walsh, A., elds22, Brivio, F. \& Frost, J. M. WMD-Group/Hybrid Perovskites: Collection 1 (Version v1.0), https://doi.org/10.5281/zenodo.2641358 (2020).

\section{Acknowledgements}

This study was authored by the National Renewable Energy Laboratory, operated by Alliance for Sustainable Energy, LLC, for the U.S. Department of Energy (DOE) under contract No. DE-AC36-08GO28308. Funding was provided by the Building Technologies Office within the U.S. Department of Energy Office of Energy Efficiency and Renewable Energy. Funding for microwave measurements provided by Department of Energy, Office of Basic Energy Sciences, Division of Chemical Sciences, Biosciences, and Geosciences. Use of the Stanford Synchrotron Radiation Lightsource, SLAC National Accelerator Laboratory, was supported by the U.S. Department of Energy, Office of Basic 
Energy Sciences under Contract No. DE-AC02-76SF00515. The views expressed in the article do not necessarily represent the views of the DOE or the U.S. Government. The U.S. Government retains and the publisher, by accepting the article for publication, acknowledges that the U.S. Government retains a nonexclusive, paid-up, irrevocable, worldwide license to publish or reproduce the published form of this study, or allow others to do so, for U.S. Government purposes. The authors thank Vincent M. Wheeler for helpful discussions. T.G.A. and G.R. thank Obadiah G. Reid for helpful discussions on fp-TRMC experiment design and data analysis. The authors thank their respective funding sources for their support.

\section{Author contributions}

B.A.R. and L.M.W. conceived the idea, designed the study, and contributed to all data interpretation. B.A.R. also contributed to all experimental work. L.E.M. and L.T.S. performed in-situ WAXS measurements and analysis. T.G.A. performed fp-TRMC measurements, and T.G.A. and G.R. interpreted the data. D.T.M. performed all ball-milling experiments. K.J.P. and C.A.W. performed and analyzed SEM measurements. B.A.R. and L.M.W. wrote the paper. L.M.W. developed the K-P-like model. All authors discussed the results and revised the paper.

\section{Competing interests}

The authors declare no competing interests.

\section{Additional information}

Supplementary information is available for this paper at https://doi.org/10.1038/s41467020-19009-z.
Correspondence and requests for materials should be addressed to L.M.W.

Peer review information Nature Communications thanks Yonghua Chen and other anonymous, reviewers for their contributions to the peer review of this work. Peer review reports are available.

Reprints and permission information is available at http://www.nature.com/reprints

Publisher's note Springer Nature remains neutral with regard to jurisdictional claims in published maps and institutional affiliations.

\section{(c) (i)}

Open Access This article is licensed under a Creative Commons Attribution 4.0 International License, which permits use, sharing, adaptation, distribution and reproduction in any medium or format, as long as you give appropriate credit to the original author(s) and the source, provide a link to the Creative Commons license, and indicate if changes were made. The images or other third party material in this article are included in the article's Creative Commons license, unless indicated otherwise in a credit line to the material. If material is not included in the article's Creative Commons license and your intended use is not permitted by statutory regulation or exceeds the permitted use, you will need to obtain permission directly from the copyright holder. To view a copy of this license, visit http://creativecommons.org/ licenses/by/4.0/.

(c) This is a U.S. Government work and not under copyright protection in the US; foreign copyright protection may apply 2020 